This document is the Accepted Manuscript version of a Published Work that appeared in final form in Macromolecules 52(18) : 6834-6848 (2019), copyright (c) 2019 American Chemical Society after peer review and technical editing by the publisher. To access the final edited and published work see https://doi.org/10.1021/acs.macromol.9b01110

\title{
Organocatalyzed polymerization of PET-mb-poly(oxyhexane) copolymers and their self-assembly into double crystalline
}

\section{superstructures}

Irma Flores ${ }^{1}$, Andere Basterretxea ${ }^{1}$, Agustin Etxeberria ${ }^{1}$, Alba González ${ }^{1}$, Connie Ocando $^{1}$, Juan Francisco Vega ${ }^{3}$, Javier Martínez-Salazar ${ }^{3}$, Haritz Sardon ${ }^{1 *}$, Alejandro J. Müller ${ }^{1,2 *}$

${ }^{1}$ POLYMAT and Polymer Science and Technology Department, Faculty of Chemistry, University of the Basque Country UPV/EHU, Paseo Manuel de Lardizabal 3, 20018, Donostia-San Sebastián, Spain.

${ }^{2}$ IKERBASQUE, Basque Foundation for Science, Bilbao, Spain.

${ }^{3}$ Biophym, Departamento de Física Macromolecular, Instituto de Estructura de la Materia, IEM-CSIC, c/ Serrano 113 bis, 28006 Madrid, Spain

*Corresponding authors: haritz.sardon@ehu.es and alejandrojesus.muller@ehu.es 


\section{ABSTRACT}

Double crystalline multi-block copolymers exhibit two well-defined melting temperatures associated with the two phases formed by their constituent blocks. The crystalline superstructure formed in these copolymers is complex and depends on the miscibility of both comonomers. In this work, an innovative series of double crystalline Poly(ethylene terephthalate)-mb-poly(oxyhexane) multiblock copolymers were prepared in one pot. Previously synthesized low molecular weight poly(oxyhexane) telechelic diol and poly(ethylene terephthalate) oligomers were reacted by transesterification using an organic catalyst (DBU:BA), in a solvent-free process. The copolymerization was demonstrated by ${ }^{1} \mathrm{H}$ NMR and ${ }^{13} \mathrm{C}$ NMR spectroscopies and the random distribution of poly(oxyhexane) chains was confirmed. We found that all compositions exhibited double crystallinity, but the crystallization of the copolymers was strongly affected by PET/poly(oxyhexane) composition. When PET content in the copolymer decreases, the crystallization and melting temperatures of the poly(oxyhexane) phase decrease as well as its crystallization rate. Poly(oxyhexane) content increases induce similar changes in the PET phase. PET and poly(oxyhexane) chain segments form a one-phase melt according to SAXS. When the material is cooled from the melt, the PET phase crystallizes first (at higher temperatures) forming superstructural (micron size spherulites) templates. Upon further cooling, the crystallization of poly(oxyhexane) lamellae occurs, within the interlamellar regions of PET spherulitic templates. Furthermore, during crystallization of the copolymer, the amorphous regions of both components undergo phase separation, as evidenced by the 
presence of two $T_{g s}$. PLOM/AFM studies were performed and demonstrated the presence of micro-spherulitic morphology in the whole composition range. Considering all results, including temperature-dependent synchrotron SAXS/WAXS, we demonstrate the ability of poly(oxyhexane) to crystallize upon cooling within the previously formed PET spherulitic templates. Hence, these copolymers form complex double crystalline spherulitic superstructures which contain two amorphous and two crystalline interlamellar phases.

Keywords: organocatalysis, poly(ether ester) copolymers, PET-mb-Poly(oxyhexane), double crystallinity, morphology. 


\section{Introduction}

Combining two or more homopolymers to obtain new materials (copolymers) with different properties from those of the parent homopolymers is a frequently used strategy. ${ }^{1}$ Poly(ethylene terephthalate) (PET) is a frequently used polymer for the manufacture of beverage bottles, amongst other multiple products. Therefore, it has been the subject of intensive research. In this sense, PET can be copolymerized with various polymers to modify its properties, for example, crystallinity, thermal stability and degree of hydrophilicity, among others. ${ }^{2}$

One possibility is to copolymerize PET with low molecular weight diols. ${ }^{3,4}$ Among the different copolymers studied, poly(ether-ester) copolymers are interesting synthetic targets because they have a "hard" segment corresponding to PET (high $T_{g}$ and $T_{m}$ ) and another "soft " segment corresponding to the polyether with (low $T_{g}$ and $T_{m}$ ). ${ }^{4,5}$ This combination results in copolymers whose properties are not a simple combination of those corresponding to the parent homopolymers. ${ }^{4-6}$ Due to all of the above, these materials have aroused scientific and industrial interest since they exhibit a wide variety of thermal behaviors that are a function of composition and chemical structure of the multiblock copolymer under consideration. ${ }^{3,5-7}$

As early as 1954, Coleman copolymerized PET with poly(ethylene glycol) (PEG) to increase its hydrophilicity and therefore facilitate its coloring. ${ }^{8}$ Similar copolymers (PETco-PEG) have been prepared for different studies, including biodegradability, phasechange characteristics, shape-memory effects, and hydrophilicity enhancement. ${ }^{3,6,7,9-12}$ 
Understanding the behavior of copolymers is complex because several probable reactions can occur during polymerization, and this can generate a large number of heterogeneities (different types of bonds between the initial monomers). ${ }^{3}$ The crystallization of multiblock copolymers is complex as both segments (hard and soft) in the copolymer may crystallize, and each component (segment) affects the properties of the other, depending on composition. ${ }^{5,6,11}$ This means that the copolymer structure can be manipulated and the properties of the material can be optimized for specific applications by adjusting the copolymerization conditions. ${ }^{9,10,12}$ For example, double crystalline copolymers have been largely employed to prepare shape-memory materials, as the control of the microstructure is crucial for shape recovery. ${ }^{13}$

Poly(ester-co-ether) copolymers are normally polymerized by high-temperature condensation reactions of low molecular weight telechelic polyether diols with polyester monomers. ${ }^{4,5,9,10}$ To date, all the multiblock poly (ester-ether) copolymers are based on polyethers with 2,3 or 4 methylene units. ${ }^{3-5,7,10,14}$ The main reason behind this limitation is that telechelic polyethers have been only prepared by the ring-opening polymerization of cyclic ethers, like oxiranes, oxetanes, or tetrahydrofuran. Larger size polyethers cannot be obtained with the previously mentioned method. The reason being the extreme stability of the corresponding cyclic ethers. ${ }^{15-17}$

Recently, attention has been paid to the synthesis of aliphatic polyethers by bulk self-condensation of alcohols, as medium-to-long molecules can be obtained. This method allows the preparation of telechelic polyethers with 6 to 12 methylene units along the chain and melting temperatures between 54 and $85^{\circ} \mathrm{C} .{ }^{18,19}$ 
In this work, PET and poly(oxyhexane) multiblock copolymers have been prepared using telechelic polyether based on 6 methylene units. The copolymers were prepared using an organic catalyst (DBU:BA), which has shown to be suitable for the transesterification of PET at elevated temperatures. ${ }^{20}$ It is expected that using telechelic polyethers with different methylene units the melting temperature of the soft polyether segment could be varied on demand obtaining double crystalline poly(ether-ester) copolymers different from the ones obtained from the ROP of the corresponding cyclic ether. To understand the behavior of these materials, the effect of the $\mathrm{PET} /$ poly(oxyhexane) ratio on the structure, nucleation, morphology, and crystallization kinetics of the segmented copolymers has been studied.

\section{Experimental}

\section{Materials}

The following reagents were purchased from Sigma-Aldrich and Fisher Scientific: Dimethyl terephthalate (DMT, $\geq 99 \%$ ), ethylene glycol (EG, 99.8\%), 1,8diazabicyclo[5.4.0]undec-7-ene (DBU, 98\%), benzoic acid (BA, 99.5\%), trifluoroacetic acid (TFA, 99\%), methanol $\left(\mathrm{CH}_{3} \mathrm{OH}, 99.5 \%\right)$ and chloroform $\left(\mathrm{CHCl}_{3}, 99.9 \%\right)$.

The polyether used was poly(oxyhexane), also denoted poly(1,6 Hexanediol) [poly (1,6 HD)], was synthesized employing the procedure reported by Basterretxea et al. ${ }^{18}$ The self-condensation of the diol (1,6 hexanediol) was carried out, the polyether was synthesized by a multistep polymerization process, using methanesulfonic acid (MSA): triazabicyclo[4.4.0]dec-5-ene (TBD) as a non-eutectic base organocatalyst. 
Following Coady et al. ${ }^{21}$, the DBU:BA catalyst was prepared at a molar ratio of base to acid (1:1). To prepare the organic salt, first, the benzoic acid was completely dissolved with ether inside a flask by stirring. Then, an addition funnel containing DBU was placed in the flask (under stirring), and the DBU was added dropwise to the solution, where the salt was observed immediately after the first drop fell in the solution. At the end of the DBU addition, stirring was continued for one hour. Subsequently, the organic salt was washed with excess ether and dried.

Synthesis of PET-mb-Poly (1,6 HD) Copolymers

The synthesis of each copolymer was performed in a tubular Schlenk flask with a magnetic stirrer. DMT (1 equiv., $0.015 \mathrm{~mol}, 3.0 \mathrm{~g}$ ) and EG (1.4 equiv., $0.021 \mathrm{~mol}, 1.3 \mathrm{~g}$ ) were blended in the presence of the DBU:BA ( 5 mol\% with respect to DMT) catalyst at $250{ }^{\circ} \mathrm{C}$ for $1.5 \mathrm{~h}$ at atmospheric pressure. Afterward, the previously synthesized telechelic poly(1,6 HD) was added to obtain copolymers of PET-mb-Poly(1,6 HD) with different compositions of PET/poly(1,6 HD). To do the above, the quantities of DMT and EG were kept constant while the content of poly $(1,6 \mathrm{HD})$ was varied as follows [PET/poly(1,6 HD), g of poly(1,6 HD)]: $(68 / 32,0.48 \mathrm{~g}),(64 / 36,1.08 \mathrm{~g}),(61 / 39,1.86)$ and (34/66, $4.34 \mathrm{~g})$. A mixing time of $1.75 \mathrm{~h}$ was used, and after this time was elapsed, vacuum was applied for $4 \mathrm{~h}$. An identical procedure was employed for the synthesis of all copolymers.

After the polymerization, the copolymers were purified by dissolving them in chloroform $\left(\mathrm{CHCl}_{3}\right)$ and trifluoroacetic acid (TFA) $(8: 1, \mathrm{v} / \mathrm{v})$ mixture, followed by precipitation in excess methanol. Then centrifugation was applied to separate impurities, and then the products were vacuum dried. 
PET-mb-Poly(1,6 HD). ${ }^{13} \mathrm{C}$ NMR ( $\left.\delta p p m, \mathrm{CDCl}_{3} / \mathrm{TFA}, 300 \mathrm{MHz}\right): 134.77$ (polyetherterephthalate-ethylene glycol, O-[ $\left[\mathrm{CH}_{2}\right]_{6}-\mathrm{COO}-\mathrm{CH}-\mathrm{Ar}-\mathrm{CH}-\mathrm{COO}-\left[\mathrm{CH}_{2}\right]_{2}-\mathrm{O}-$ ), 134.55 (Dyad polyether-terephthalate-polyether, $\quad \mathrm{O}-\left[\mathrm{CH}_{2}\right]_{6}-\mathrm{COO}-\mathrm{CH}-\mathrm{Ar}-\mathrm{CH}-\mathrm{COO}-\left[\mathrm{CH}_{2}\right]_{6}-\mathrm{O}-\mathrm{-}, \quad 134.19$ (Dyad ethylene glycol-terephthalate-ethylene glycol, O-[ $\left.\mathrm{CH}_{2}\right]_{2}-\mathrm{COO}-\mathrm{CH}-\mathrm{Ar}-\mathrm{CH}-\mathrm{COO}-$ $\left[\mathrm{CH}_{2}\right]_{2}-\mathrm{O}-$ ), 133.97 (ethylene glycol-terephthalate-polyether, O-[ $\left.\mathrm{CH}_{2}\right]_{6}-\mathrm{COO}-\mathrm{CH}-\mathrm{Ar}-\mathrm{CH}-$ $\left.\mathrm{COO}-\left[\mathrm{CH}_{2}\right]_{2}-\mathrm{O}\right)$.

\section{Characterization}

NMR Spectroscopy

${ }^{1} \mathrm{H}$ NMR and ${ }^{13} \mathrm{C}$ NMR spectra were collected in a Bruker DPX300 spectrometer. A mixed solvent was used consisting in deuterated chloroform $\left(\mathrm{CDCl}_{3}\right)$ and trifluoroacetic acid (TFA) (8:1, v/v) to dissolve PET and PET-mb-Poly(1,6 HD) copolymers. For poly $(1,6 \mathrm{HD})$, deuterated chloroform $\left(\mathrm{CDCl}_{3}\right)$ was used. $\mathrm{CDCl}_{3}$ was employed as a reference for all spectra. For ${ }^{1} \mathrm{H}$ NMR measurements, a $10 \mathrm{mg}$ sample in $0.6 \mathrm{~mL}$ of solvent was employed. On the other hand, for ${ }^{13} \mathrm{C}$ NMR analysis, a $40 \mathrm{mg}$ sample in $0.6 \mathrm{~mL}$ of solvent was used.

Size Exclusion Chromatography (SEC)

SEC was performed at $40^{\circ} \mathrm{C}$ in an Agilent equipment for PET and PET- $m b$-poly $(1,6$ HD) samples. The equipment was fitted with a refractive index detector and with a precolumn HFIP-LG and two HFIP 804 and HFIP 803 columns from Shodex. The columns were packed with polystyrene-divinylbenzene. The solvent employed was $1,1,1,3,3,3-$ Hexafluoro-2-propanol (HFIP) with a flow of $0.5 \mathrm{~mL} \cdot \mathrm{min}^{-1}$. 
In the case of the polyether, the sample was analyzed by SEC analysis (Agilent PLGPC 50) using Shodex GPC HFIP-803 (300 x 8.0mm), where the chloroform was the eluent, at $50{ }^{\circ} \mathrm{C}$ and a flow rate of $1 \mathrm{~mL} / \mathrm{min}$ was employed. Polystyrene standards were used as calibration materials.

Intrinsic Viscosity

The determination of the intrinsic viscosity was carried out following the standard procedure given by UNE-EN ISO 1628 / 5-1986 (E) in a Ubbelhod capillary viscometer. A solution with a polymer concentration of $0.2 \mathrm{~g} / \mathrm{dL}$ was prepared, the solvent used was a mixture of phenol and 1,2-dichlorobenzene (50/50 \%w). The temperature of the bath to carry out the measurements was $30^{\circ} \mathrm{C}$. A chronometer was used to measure the flow time; at least three measurements for each sample were made. The values reported are the average of the values obtained from the reduced viscosity and the inherent viscosity. Different authors report the formulas to determine the different viscosities. ${ }^{22}$

Dynamic Mechanical Thermal Analysis (DMTA)

A Triton 2000 DMA (Triton Technology), was employed using single cantilever fixtures in bending mode. The materials were analyzed in powder form by using material pockets. ${ }^{23,24}$ The powder was placed inside a metal pocket which is then folded in half and close to form a small sandwich-like specimen. Analysis conditions included a temperature range from $-100{ }^{\circ} \mathrm{C}$ to $200^{\circ} \mathrm{C}$, at a $3^{\circ} \mathrm{C} / \mathrm{min}$ heating rate and $1 \mathrm{~Hz}$ frequency. These tests usually give a relatively high signal/noise ratio, but they are good enough to 
detect glass transition temperatures $\left(T_{g}\right)$, by employing the peak value in the loss tangent $(\tan \delta)$.

Differential Scanning Calorimetry (DSC)

A DSC 8500 with a nitrogen flow of $20 \mathrm{~mL} / \mathrm{min}$ was used (PerkinElmer), and it was calibrated with tin and indium high purity standards. Samples of 4.5-5.5 mg were employed, and all scanning rates were $20^{\circ} \mathrm{C} / \mathrm{min}$. Samples were scanned using a temperature range from -20 to $270^{\circ} \mathrm{C}$.

The reported peak melting temperature $\left(T_{m}\right)$ and heat of fusion $\left(\Delta H_{m}\right)$ were measured during the second heating runs. The reported values of the peak crystallization temperature $\left(T_{c}\right)$ and its corresponding crystallization enthalpy $\left(\Delta H_{c}\right)$, were taken from the cooling scans.

Flash DSC

A Flash DSC 2+ (Mettler Toledo) is a chip calorimeter for fast differential scanning calorimetry analysis. This equipment was used to determine the glass transition temperatures of some copolymers made from PET and Poly(1,6 HD). The flash DSC 2+ was equipped with Huber TC-100 intracooler. The cooling rate employed was $-4000 \mathrm{~K} / \mathrm{s}$, and the heating rate was $20,000 \mathrm{~K} / \mathrm{s}$. The reason for using the Flash DSC2+ was twofold. Firstly, by applying a very fast cooling rate $(-4,000 \mathrm{~K} / \mathrm{s})$ most samples were quenched to the amorphous state (or their crystallinity was greatly reduced), thereby facilitating the detection of their glass transition upon subsequent heating. Secondly, by employing fast heating rates, we were also able to avoid cold-crystallization in most samples. We successfully prevented PET and the PET phase in the copolymers to crystallize or melt 
during cooling or heating. In the case of the polyether phase, whose crystallization kinetics is faster than PET, its crystallinity was greatly reduced.

Before each experiment, the sensor was conditioned and calibrated, after a flow of nitrogen gas was applied to perform the measurements under an inert atmosphere, maintaining an $80 \mathrm{~mL} / \mathrm{min}$ flow rate. For a good contact between the sample and the sensor, the sample was subjected to several heating and cooling runs from 25 to $270{ }^{\circ} \mathrm{C}$ (rate of $1000 \mathrm{~K} / \mathrm{s}$ ). The samples were analyzed in a range of -90 to $270{ }^{\circ} \mathrm{C}$. The reported values of $T_{g}$ were taken from the heating runs. As the mass employed in fast chip calorimeter experiments is so small, the results are assumed to be independent of sample mass. The STARe software was used to analyze the data.

Simultaneous Wide-Angle and Small-Angle X-ray Scattering (WAXS/SAXS)

The samples were inserted in capillaries and were analyzed under nonisothermal conditions by simultaneous WAXS/SAXS. The experiments were performed at the ALBA Synchrotron radiation facility (Barcelona, Spain), using beamline BL11-NCD. The capillaries were placed inside a hot stage equipped with liquid nitrogen cooling system (THMS600). For PET-mb-Poly(1,6 HD) samples, the WAXS/SAXS patterns were collected during cooling from $270^{\circ} \mathrm{C}$ to $-20^{\circ} \mathrm{C}$ and subsequently heating from $-20^{\circ} \mathrm{C}$ to $270^{\circ} \mathrm{C}$. For poly $(1,6 \mathrm{HD})$ the temperature range was: cooling from $130{ }^{\circ} \mathrm{C}$ to $-20^{\circ} \mathrm{C}$ and subsequent heating from $-20^{\circ} \mathrm{C}$ to $130^{\circ} \mathrm{C}$. A scanning rate of $20^{\circ} \mathrm{C} / \mathrm{min}$ (both for cooling and heating) was employed, so that the results could be compared to non-isothermal DSC scans performed at identical scanning rates.

A $12.4 \mathrm{keV}(\lambda=1.0 \AA$ A $\mathrm{X}$-ray source was employed. A Rayonix LX255-HS detector was employed to detect WAXS, with an $85 \times 255 \mathrm{~mm}^{2}$ (pixel size $40 \times 40 \mu \mathrm{m}^{2}$ ) active area. 
For PET-mb-Poly(1,6 HD) copolymers, the sample-to-detector distance was set to $154.69 \mathrm{~mm}$ with $29.23^{\circ}$ tilt angle. To analyze poly(1,6 HD), the sample-to-detector distance was $196.14 \mathrm{~mm}$, and the tilt angle $30.33^{\circ}$.

A Pilatus 1M detector (from Dectris) was used for SAXS, with $168.7 \times 179.4 \mathrm{~mm}^{2}$ (pixel size $172 \times 172 \mu \mathrm{m}^{2}$ ) active area. The sample-to-detector distance was set to 6730 $\mathrm{mm}$ with a $0^{\circ}$ tilt angle for measurements of PET-mb-Poly $(1,6 \mathrm{HD})$ samples. When poly $(1,6 \mathrm{HD})$ was analyzed, the sample-to-detector distance was changed to $6790 \mathrm{~mm}$ with $0^{\circ}$ tilt angle. Plots of scattering intensity vs. scattering vector were obtained. Silver behenate (SAXS) and chromium (III) oxide (WAXS) were employed for calibration purposes.

Thermogravimetric analysis (TGA)

A TGA Q500 (TA instrument) under nitrogen atmosphere was used to measure the thermal stability of the materials. Samples of 5-10 mg were heated from 40 to 600 ${ }^{\circ} \mathrm{C}$ at a rate of $10^{\circ} \mathrm{C} / \mathrm{min}$.

Polarized Light Optical Microscopy (PLOM) and Atomic Force Microscopy (AFM)

The morphology was studied by Polarized Light Optical Microscopy (PLOM) and Atomic Force Microscopy (AFM). A Nikon Eclipse E600 PLO microscope and a Nikon digital camera DXM200 were employed coupled to a METLER hot stage.

After samples crystallization, AFM observations were performed employing a $\mu_{T A}{ }^{\mathrm{TM}} 2990$ Micro-Thermal Analyzer. Contact mode was employed for topography images with a set point of $-2.5 \mathrm{nA}$. The cantilever deflection is kept constant by a feedback loop at the selected set point value during scanning. This is performed by the application of a constant voltage (50 V) to the Z-piezo. Silicon nitride tips with V-shaped 
(Applied NanoStructures, Inc., Mountain View, CA, USA) were employed. The had a cantilever length of $200 \mu \mathrm{m}$ and a spring constant of $0.046 \mathrm{~N} \cdot \mathrm{m}^{-1}$. Scanning rates varied from 3 to $50 \mu \mathrm{m} \cdot \mathrm{s}^{-1}$ depending on image sizes. The $\mu$ TALab 1.01 software package was used for image processing.

Film samples were prepared by solvent casting from HFIP (c $=25 \mathrm{mg} / \mathrm{mL}$ ) solutions prepared at room temperature. $20 \mu \mathrm{L}$ aliquots of the solutions were cast onto glass substrates. Then, the solvent was allowed to evaporate completely, and the samples were dried in vacuum. The samples were heated to temperatures of $10{ }^{\circ} \mathrm{C}$ above the DSC peak melting point during 2 minutes, to erase thermal history. Different isothermal crystallization protocols were applied to the samples: at $T_{c}$ (as measured by DSC) and at two different levels of undercooling $\left(\Delta T=16^{\circ} \mathrm{C}\right.$ and $\Delta T=7^{\circ} \mathrm{C}$, during 2 hours). After crystallization, samples were quenched to $25 \mathrm{C}$.

\section{Results and discussion}

Synthesis and Characterization of Copolymers

To prepare poly(ether-ester) copolymers, that can show double crystallinity, first low molecular weight telechelic poly $(1,6 \mathrm{HD})$ has been synthesized using the procedure previously reported. ${ }^{18}$ Briefly, poly(oxyhexane) diol [poly(1,6 HD)] has been synthesized by the step-growth polymerization of 1,6 hexanediol using an organocatalyst consisting of non-eutectic acid-base mixtures (NEMO), as previously described, obtaining telechelic poly $(1,6 \mathrm{HD})$ with $M_{n} \approx 3,500 \mathrm{~g} / \mathrm{mol}$ (measured by SEC). ${ }^{18}$ The transesterification reaction between PET oligomers and telechelic poly(1,6 HD) was carried out using an organic catalyst (DBU:BA), which was selected based on its demonstrated effectiveness in the 
homopolymerization of PET and the copolymerization of PET with other polyesters. 20,23,25 The synthesis of PET-mb-poly(1,6 HD) was carried out in two steps. First, the reaction between dimethyl terephthalate (DMT) and excess ethylene glycol (EG) was performed with the (DBU:BA) organocatalyst to form oligomers of PET for $1.5 \mathrm{~h}$. Then, poly(1,6 HD) was added to PET oligomers (see Scheme 1) to produce the PET-mbpoly $(1,6 \mathrm{HD})$ multi-block copolymers. The polymerization process has been performed in two-steps to facilitate the formation of pure PET oligomers able to crystallize.

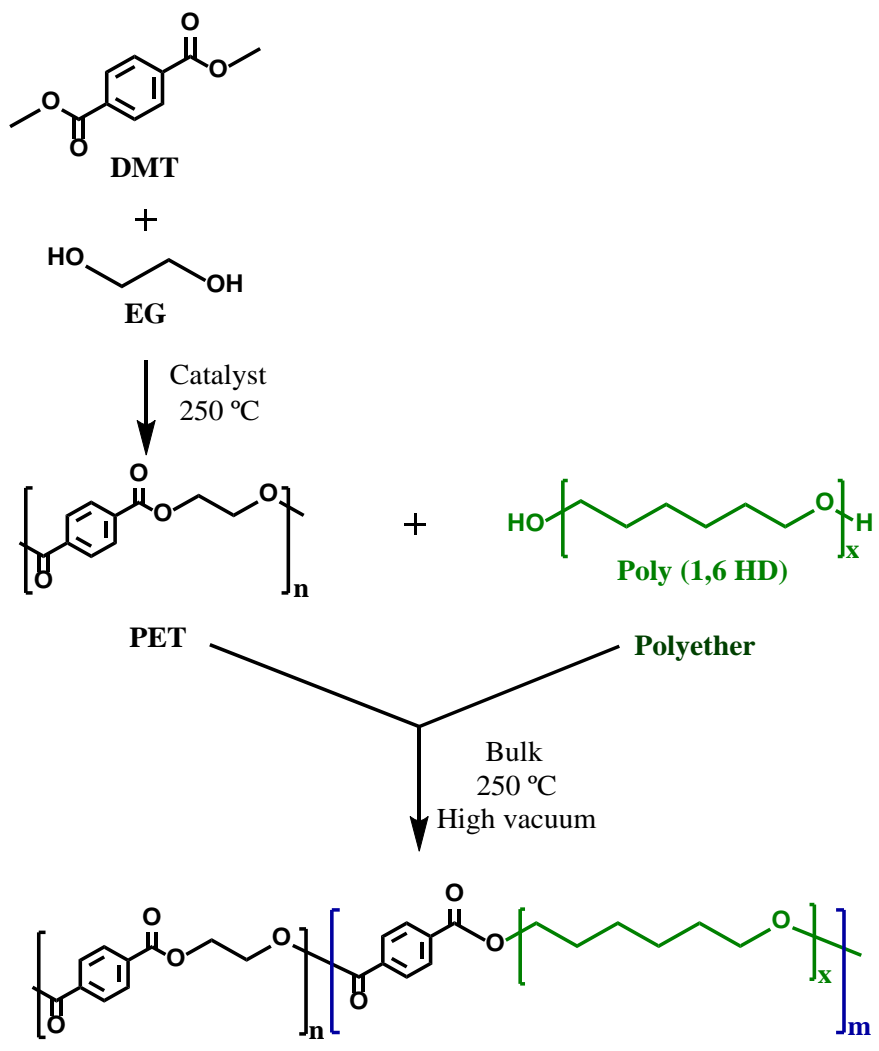

Scheme 1. Organocatalyzed Synthesis of PET-mb-Poly(1,6 HD).

${ }^{1} \mathrm{H}$ NMR and ${ }^{13} \mathrm{C}$ NMR were used to confirm the copolymerization between PET and Poly(1,6 HD). Figure 1 shows an ${ }^{1} \mathrm{H}$ NMR spectrum of a copolymer of PET with poly $(1,6 \mathrm{HD})$. The characteristic peaks from PET units (4.78 ppm, $\left.\mathrm{COO}-\mathrm{CH}_{2}-\mathrm{CH}_{2}-\mathrm{OCO}\right)$ and poly(1,6 HD) units (3.63 ppm, -O-[ $\left.\mathrm{CH}_{2}-\left(\mathrm{CH}_{2}\right)_{4}-\mathrm{CH}_{2}-\mathrm{O}-\right], 1.63 \mathrm{ppm},-\mathrm{O}-\left[\mathrm{CH}_{2}-\mathrm{CH}_{2^{-}}\left(\mathrm{CH}_{2}\right)_{2^{-}}\right.$ 
$\left.\mathrm{CH}_{2}-\mathrm{CH}_{2}-\mathrm{O}-\right]$ and $1.34 \mathrm{ppm},-\mathrm{O}-\left[\left(\mathrm{CH}_{2}\right)_{2}-\mathrm{CH}_{2}-\mathrm{CH}_{2}-\left(\mathrm{CH}_{2}\right)_{2}-\mathrm{O}-\right]$ can be appreciated in Figure 1. ${ }^{18,20}$ In addition, a new set of peaks can be observed in the ${ }^{1} \mathrm{H}$ NMR spectra related to the PET-mb-Poly(1,6 HD) links at 4.40 ppm (peak 1), assigned to terephthalate-polyether (Ar- $\mathrm{CH}-\mathrm{COO}-\mathrm{CH}_{2}-\mathrm{CH}_{2}-\mathrm{CH}_{2}-\mathrm{CH}_{2}-\mathrm{CH}_{2}-\mathrm{CH}_{2}-\mathrm{O}$ ) ${ }^{10}$ and at $8.12 \mathrm{ppm}$ corresponding to terephthalate-polyether (Ar- $\left.\mathrm{CH}-\mathrm{COO}-\left[\mathrm{CH}_{2}\right]_{6}-\mathrm{O}-\right)$ and terephthalate-ethylene glycolpolyether ( $\left.\mathrm{Ar}-\mathrm{CH}-\mathrm{COO}-\mathrm{CH}_{2}-\mathrm{CH}_{2}-\mathrm{O}-\left[\mathrm{CH}_{2}\right]_{6}-\mathrm{O}-\right)$. In the latest, the signal of PET-mb-Poly $(1,6$ HD) link seems to be overlapped with the Ar-CH signal corresponding to neat PET. Therefore, it is not convincingly possible to assign a single signal to this position, but signal splitting suggests the presence of PET-mb-Poly(1,6 HD).

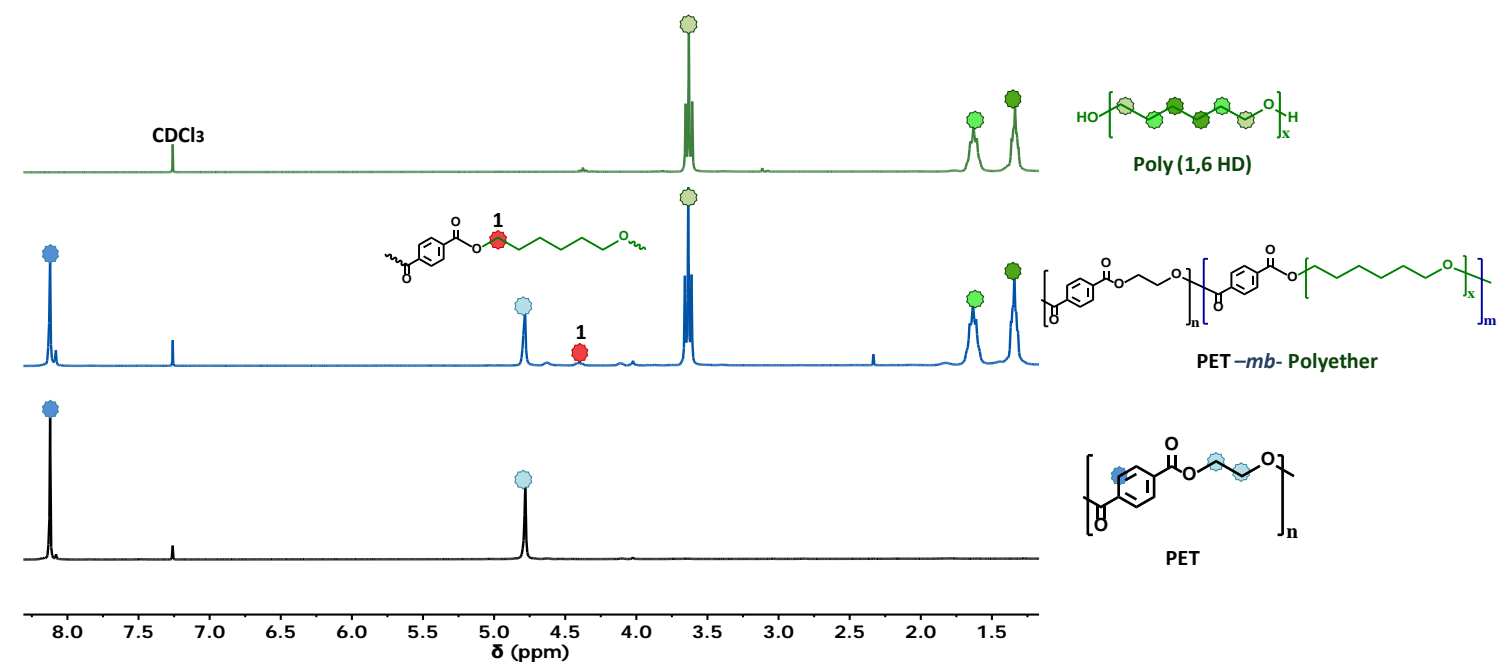

Figure 1. ${ }^{1} \mathrm{H}$ NMR spectrum of $\mathrm{PET}_{34} \mathrm{Poly}(1,6 \mathrm{HD})_{66}$ in $\mathrm{CDCl}_{3} / \mathrm{TFA}$.

The presence of covalent bonds between PET and poly $(1,6 \mathrm{HD})$ was further confirmed by ${ }^{13} \mathrm{C}$ NMR experiments (Figure 2). Looking at the signal corresponding to quaternary $\mathrm{C}$ centered at $134 \mathrm{ppm}$ of the aromatic ring, a different chemical environment of the copolymer dyads is reflected. The signals at 134.55 and $134.19 \mathrm{ppm}$ correspond to polyether-terephthalate-polyether (PE-PE) and ethylene glycol- 
terephthalate-ethylene glycol dyads (EG-EG), respectively, while the signals at 134.77 and $133.97 \mathrm{ppm}$ correspond to interchange dyads: polyether-terephthalate-ethylene glycol (PE-EG or EG-PE). However, because only copolymers rich in polyether (\% mol superior to 10) showed clearly these signals, two additional copolymers were synthesized to adequately characterize the copolymer microstructure: $\mathrm{PET}_{03} \mathrm{Poly}(1,6$ $\mathrm{HD})_{97}$ and $\mathrm{PET} \mathrm{T}_{01}$ Poly$(1,6 \mathrm{HD})_{99}$. As expected, when the amount of Poly(1,6 HD) increases in the sample, the signal at $134.19 \mathrm{ppm}$ decreases, while the signal at $134.55 \mathrm{ppm}$ increases, confirming the covalent bond between PET and poly(oxyhexane).
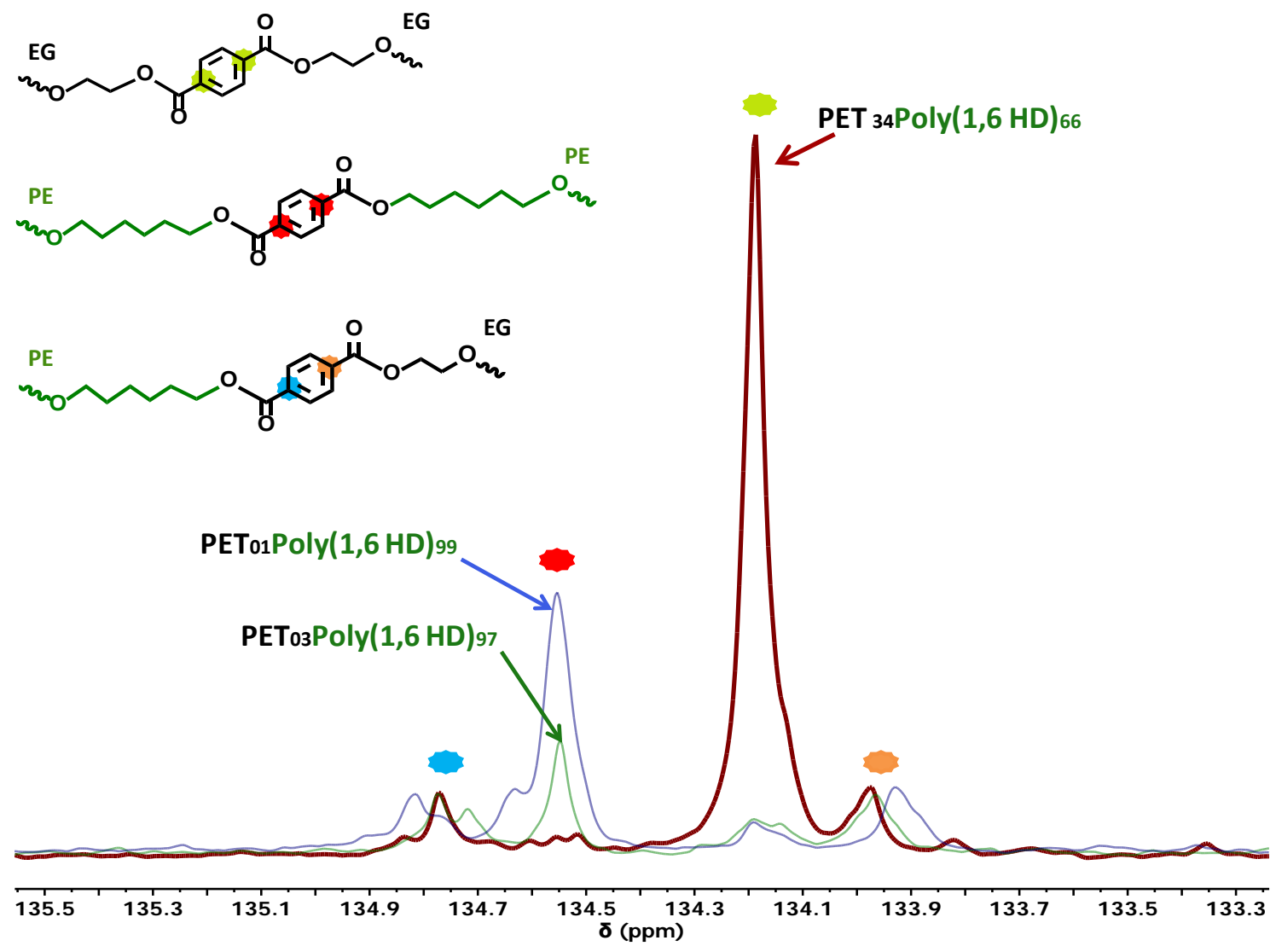

Figure 2. ${ }^{13} \mathrm{C}$ NMR spectrum of PET- $m b$-Poly $(1,6 \mathrm{HD})$ in $\mathrm{CDCl}_{3} / \mathrm{TFA}$.

Once the successful copolymerization of PET with Poly $(1,6$ HD) was demonstrated, copolymers with different compositions PET-mb-Poly(1,6 HD) were 
prepared, to compare the properties of the copolymers and verify if the composition significantly affects the thermal properties and crystallization of the final materials.

The experimental values of number average sequential length $\left(L_{i}\right)$ and the degree of the randomness $(\eta)$ were obtained using data from ${ }^{13} \mathrm{C}$ NMR (equations in Supporting Information). It is appreciated that for the copolymers shown in Figure 2, the value of $\eta$ tends to 1 , indicating that ethylene glycol and polyether are reacting randomly with terephthalic units (Table S.2.). Taking into account the polymeric nature of poly(1,6 HD), the random reaction leads to the multi-block copolymer formation, where each of the different blocks forming the copolymer is randomly distributed.

Considering that all the obtained experimental values of $\eta$ were close to 1 for compositions of 9 to 80 mol\% of poly $(1,6 \mathrm{HD})$ present in the copolymer (Table S.1), it seems feasible that copolymers with a molar percentage of poly $(1,6 \mathrm{HD})$ between 0 and $9 \%$ will also have a random character (in these cases, the intensities of the signals corresponding to the interchange PE-EG dyad were so small that prevented the quantitative calculation of the copolymer random character).

Assuming that all copolymers have a random distribution of their blocky structures, the theoretical number of average sequence length for copolymers with molar percentages lower than $9 \%$ of poly $(1,6 \mathrm{HD})$ were calculated. The results are shown in Table 1. In the case of PET-mb-Poly(1,6 HD) copolymers, the parameter $L_{E G}$, which represents units of PET, decreases from 38 to 10 , in a range of poly $(1,6 \mathrm{HD})$ content from 0 to 10 mol\%, while $L_{P E}$ varies from 1 to 1.1 , which means that practically all the Poly(1,6 HD) units are isolated. 
Table 1 Composition, number average sequential length, and intrinsic viscosity of synthesized homopolymers and copolymers

\begin{tabular}{|c|c|c|c|c|c|c|c|}
\hline \multirow[b]{2}{*}{ Sample } & \multicolumn{2}{|c|}{ PET / Poly(1,6 HD) } & \multicolumn{2}{|c|}{$\begin{array}{l}\text { Number average } \\
\text { sequential length }^{\mathrm{a}}\end{array}$} & \multirow[b]{2}{*}{$\eta^{\mathrm{a}}$} & \multirow[b]{2}{*}{$\begin{array}{l}I . V^{b} \\
\text { (dL/g) }\end{array}$} & \multirow[b]{2}{*}{$\begin{array}{l}M n \\
K D a\end{array}$} \\
\hline & $\begin{array}{l}\% \text { mass } \\
\text { ratio }^{a}\end{array}$ & $\begin{array}{l}\% \text { mol } \\
\text { ratio }\end{array}$ & $\begin{array}{l}L_{E G} \\
\text { (PET) }\end{array}$ & $\begin{array}{c}L_{P E} \\
\text { Poly }(1,6 \mathrm{HD})\end{array}$ & & & \\
\hline PET & $100 / 0$ & $100 / 0$ & --- & --- & --- & $0.23( \pm 0.02)$ & 3.5 \\
\hline $\operatorname{PET}_{68}$ Poly $(1,6 \text { HD })_{32}$ & $68 / 32$ & $97.4 / 2.6$ & 38.6 & 1.03 & --- & $0.31( \pm 0.01)$ & 4.9 \\
\hline $\mathrm{PET}_{64}$ Poly $(1,6 \mathrm{HD})_{36}$ & $64 / 36$ & $97 / 03$ & 33.4 & 1.03 & --- & $0.40( \pm 0)$ & 5.0 \\
\hline PET $_{61}$ Poly $(1,6 \text { HD })_{39}$ & $61 / 39$ & $96.5 / 3.5$ & 28.9 & 1.04 & --- & $0.42( \pm 0.02)$ & 4.9 \\
\hline $\operatorname{PET}_{34} \operatorname{Poly}\left(1,6 \mathrm{HD}_{66}\right.$ & $34 / 66$ & $90 / 10$ & 10.4 & 1.11 & 0.99 & $0.45( \pm 0.01)$ & 4.4 \\
\hline Poly(1,6 HD) & $0 / 100$ & $0 / 100$ & --- & --- & --- & $0.10( \pm 0.02)$ & --- \\
\hline
\end{tabular}

${ }^{a}$ Calculated by NMR only for $\mathrm{PET}_{34} \mathrm{Poly}(1,6 \mathrm{HD})_{66}$ sample. For the rest of copolymers, assuming their random character $(\eta \sim 1)$, theoretical values of $L_{i}$ are given. In the case of $L_{P E}$ the second decimal is given

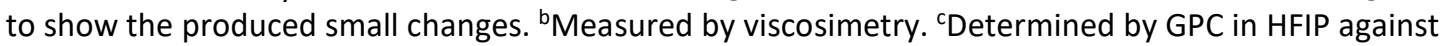
PMMA standards for PET and copolymers.

To measure the molecular weights of the copolymers by GPC, first, a solvent (HFIP) that diluted both components of the copolymer (PET and poly $(1,6 \mathrm{HD})$ ) was used.

Nevertheless, we realized that the polymers were degrading during the measurements, and the obtained molecular weights were underestimated. On the other hand, when a conventional solvent $\left(\mathrm{CHCl}_{3}\right)$ able to dissolve the poly(1,6 $\left.\mathrm{HD}\right)$ was used, the polymers were only partially soluble and very low molecular weight values were also obtained. For this reason, the intrinsic viscosity of the materials was measured.

Table 1 shows the values of intrinsic viscosity (I.V.) for homopolymers and copolymers. For the series of copolymers of PET with poly $(1,6 \mathrm{HD})$, the viscosity seems to increase, which indicates a molecular weight increase of the copolymers when the poly $(1,6 \mathrm{HD})$ is bound to PET. This result can also be taken as proof that PET and 
polyether copolymerized and as a consequence, generate materials with viscosities higher than those of the parent homopolymers.

At the temperatures employed to synthesize the copolymers, transesterification reactions could have ocurred. In this case, these reactions would break the poly(oxyhexane) blocks leading to the reduction of the number average sequential length. However, the data reported in Table 1 shows that all the values are slightly superior to 1 , which corresponds to the initial value of the poly(oxyhexane). Therefore, it can be deduced that transesterification reactions (if any) have not progressed substantially. In this particular case as we did not observe any chain etherification, the ether bonds remain untouched and we are able to observe double crystallinity in our copolymers due to the presence of the two segments rich in polyether and rich in polyester.

\section{Effect of PET/Poly(1,6 HD) composition on the Thermal Properties of Copolymers}

Figure 3 shows the DSC curves from (a) cooling and (b) second heating scans obtained from the homopolymers and copolymers of PET-mb-Poly(1,6 HD). All compositions show curves with two peaks. In the case of $\operatorname{PET}_{68} \operatorname{Poly}(1,6 \mathrm{HD})_{32}$, a close-up had to be used to reveal the presence of the polyether crystallization and melting. The higher temperature peaks are attributed to the PET phase while the lower temperature ones to the poly $(1,6 \mathrm{HD})$ phase. It is observed that when the amount of poly $(1,6 \mathrm{HD})$ increases in the copolymer, the peak intensity corresponding to the poly $(1,6 \mathrm{HD})$ phase increases and the peak intensity corresponding to the PET phase decreases. 

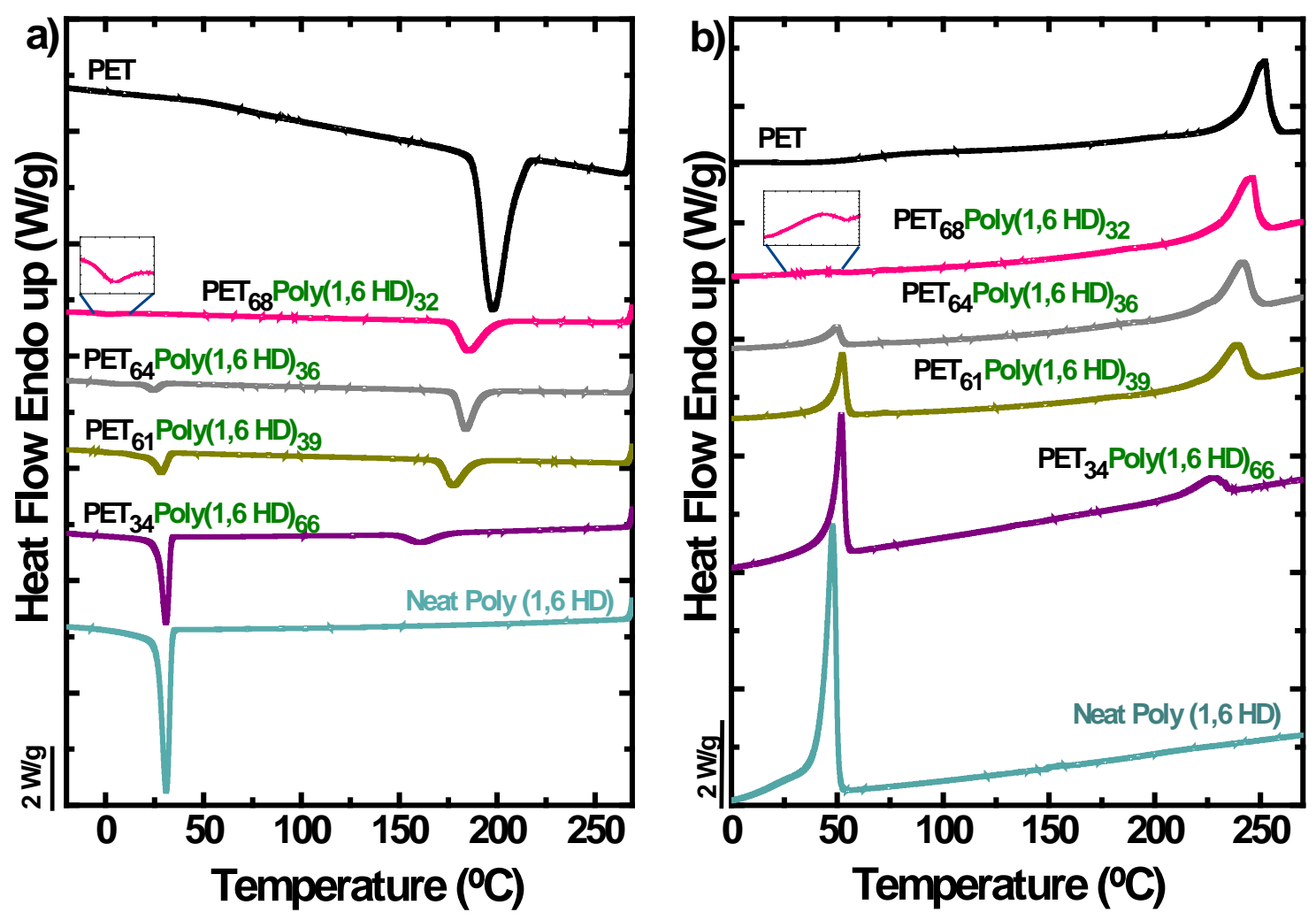

Figure 3. DSC scans: (a) cooling and (b) second heating for the PET-mb-Poly $(1,6 \mathrm{HD})$ copolymers and the parent homopolymers.

In addition, it is observed that when the amount of PET increases in the copolymer, the $T_{m}$ of the poly $(1,6 \mathrm{HD})$ crystals decreases. This could be because the PET phase crystallizes first upon cooling from the melt, and if its content is large, it can induce confinement effects on the poly $(1,6 \mathrm{HD})$ chains that limit its crystallization and lamellar thickness (which is proportional to $\left.T_{m}\right)$. On the other hand, when the amount of poly $(1,6$ HD) increases, the $T_{m}$ of the PET crystals decreases as the average length of the linear crystallizable PET sequences decrease, as determined by NMR and reported in Table 1. $6,7,11$ 
Table 2 Thermal Properties of Synthesized Polymers.

\begin{tabular}{|c|c|c|c|c|c|c|c|c|}
\hline \multirow[b]{3}{*}{ Sample } & \multicolumn{4}{|c|}{ Cooling } & \multicolumn{4}{|c|}{ 2nd. Heating } \\
\hline & \multicolumn{2}{|c|}{ PET } & \multicolumn{2}{|c|}{ Poly $(1,6 \mathrm{HD})$} & \multicolumn{2}{|c|}{ PET } & \multicolumn{2}{|c|}{ Poly $(1,6 \mathrm{HD})$} \\
\hline & $\begin{array}{c}T_{c} \\
\left({ }^{\circ} \mathrm{C}\right)^{\mathrm{a}}\end{array}$ & $\begin{array}{c}\Delta H_{c} \\
(\mathrm{~J} / \mathrm{g})^{\mathrm{a}}\end{array}$ & $\begin{array}{c}T_{c} \\
\left({ }^{\circ} \mathrm{C}\right)^{\mathrm{a}}\end{array}$ & $\begin{array}{c}\Delta H_{c} \\
(\mathrm{~J} / \mathrm{g})^{\mathrm{a}}\end{array}$ & $\begin{array}{c}T_{m} \\
\left({ }^{\circ} \mathrm{C}\right)^{\mathrm{a}}\end{array}$ & $\begin{array}{c}\Delta H_{m} \\
(\mathrm{~J} / \mathrm{g})^{\mathrm{a}}\end{array}$ & $\begin{array}{c}T_{m} \\
\left({ }^{\circ} \mathrm{C}\right)^{\mathrm{a}}\end{array}$ & $\begin{array}{c}\Delta H_{m} \\
(\mathrm{~J} / \mathrm{g})^{\mathrm{a}}\end{array}$ \\
\hline PET & 197.9 & -54 & - & - & 252 & 53 & - & - \\
\hline PET $_{68}$ Poly(1,6 HD $)_{32}$ & 185.5 & -66 & 1.3 & -6 & 246.1 & 62 & 42.7 & 6 \\
\hline PET $_{64}$ Poly $(1,6 \text { HD })_{36}$ & 183.9 & -62 & 24.4 & -25 & 241.3 & 56 & 49.7 & 28 \\
\hline PET $_{61}$ Poly $(1,6 \text { HD })_{39}$ & 177.5 & -51 & 28.3 & -56 & 238.6 & 49 & 52.3 & 56 \\
\hline $\mathrm{PET}_{34}$ Poly $(1,6 \text { HD })_{66}$ & 160.6 & -44 & 30.7 & -71 & 227.1 & 38 & 51.9 & 74 \\
\hline Poly(1,6 HD)* & - & - & 30.9 & -100 & - & - & 47.7 & 110 \\
\hline
\end{tabular}

a Determined by DSC. *This is a polyether sample that was submitted to the same conditions of time and temperature as the copolymer samples, but without the presence of PET.

${ }^{*} \Delta H_{c}$ and $\Delta H_{m}$ are normalized values, they were calculated by dividing the enthalpy by the respective mass fraction of the component that crystallizes (PET or Poly(1,6 HD)).

Table 2 displays $T_{c}$ and $T_{m}$ values. $\Delta H_{m}$ was employed to calculate the degree of crystallinity $\left(X_{c}\right)$ of the phases (PET or poly $\left.(1,6 \mathrm{HD})\right)$ at room temperature. $X_{c}$ is calculated using the enthalpy of fusion of the corresponding phase $\left(\Delta H_{m}\right)$, the weight fraction of the phase under consideration $(W)$, and the enthalpy of fusion of a $100 \%$ crystalline sample by Eq. (1).

$$
X_{c}=\frac{\Delta H_{m}}{\Delta H_{m(100 \%)} W}
$$

The value of $\Delta H_{m(100 \%)}$ for poly $(1,6 \mathrm{HD})$ was calculated following the procedure reported in the literature $[250 \mathrm{~J} / \mathrm{g}$ for poly $(1,6 \mathrm{HD})] .{ }^{26}$ In the case of PET, a value of 140 $\mathrm{J} / \mathrm{g}$ was used, as reported elsewhere. ${ }^{27}$

The results of the non-isothermal analysis are summarized in Figure 4, where $T_{c}$, $T_{m}$, and $X_{c}$ (degree of crystallinity) are plotted as a function of the poly $(1,6 \mathrm{HD})$ or PET content in the copolymers. Figure 4 a shows that by increasing polyether content in the copolymer, $T_{m}$ and $T_{c}$ of the PET component decrease. As SAXS analysis will show below, the copolymers are miscible in the melt, so it is reasonable that their first-order phase 
transitions change with composition, as there a dilution effect is present. For instance, the PET component within the copolymers is the first to crystallize upon cooling from the melt, when the polyether phase is molten. Clearly, a $T_{c}$ depression will be expected. A $T_{m}$ depression is also expected, as when the heating scan is performed, the polyether phase melts first, leaving the crystals of the PET phase to melt surrounded by liquid polyether chains that can provoke a dilution effect (a depression of the melting point).

In the case of the polyether rich phase, although similar thermodynamic effects could be expected, the polyether can only crystallize after the PET-rich phase crystallizes. As shown below, the PET-rich phase forms a superstructural semi-crystalline template, where the polyether can only crystallize (upon cooling) within the interlamellar regions of the previously crystallized PET. In this case, confinement effects can dominate the crystallization when the content of polyether decreases in the copolymer.

In the case of the crystallinity degree determined by DSC (Figure 4b), the error in the measurements must be taken into account (approximately 10-15\%). The errors depend on: the sensitivity of the heat capacity measurement, the integration of the curves, the calibration of the equipment, and the error given by the baseline drift. Therefore, the PET-rich phase seems to be crystallizing around $40 \%$ until the amount of polyether reaches $66 \%$ by weight, when the crystallinity drops to about $26 \%$. The effect of PET on the crystallinity of the polyether phase is much more dramatic, as expected given the confinement effect plus the anti-plasticization caused by partial miscibility with much less flexible PET chains. 
a)

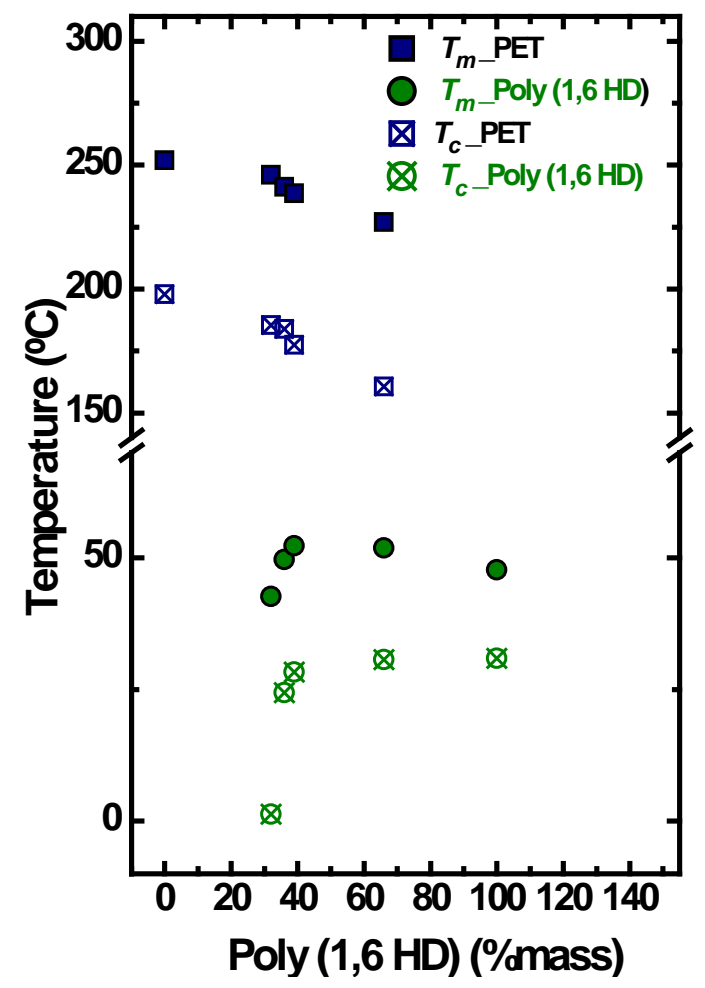

b)

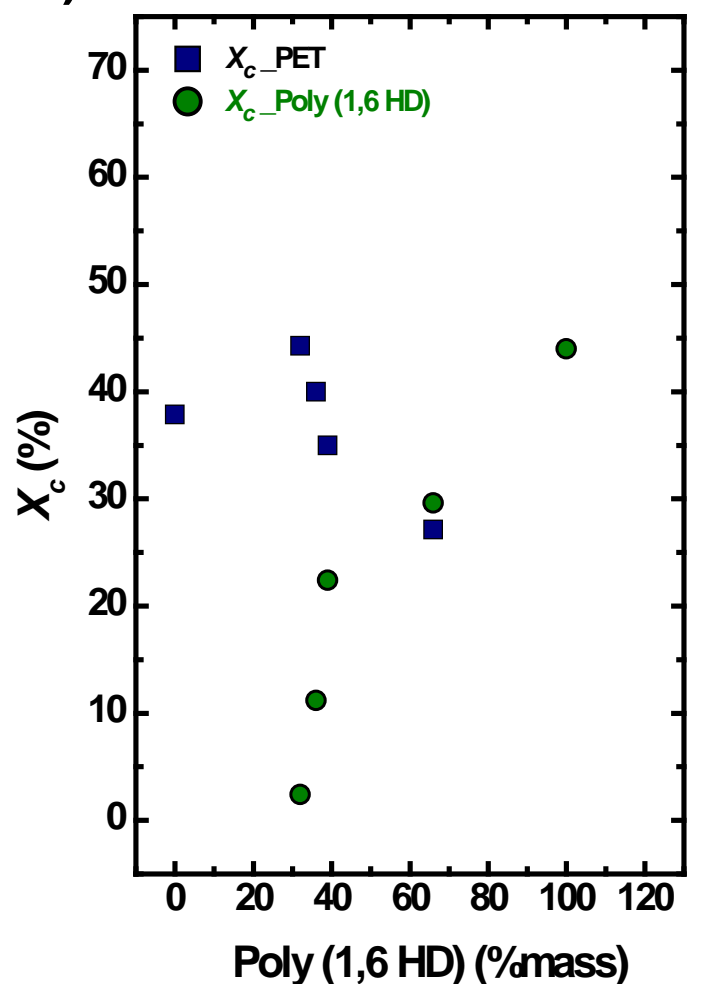

Figure 4. (a) Values of $T_{m}$ and $T_{c}$ as a function of composition for PET- $m b$-Poly $(1,6 \mathrm{HD})$ and (b) $X_{c}$ versus composition for PET-mb-Poly(1,6 HD).

Figure 5 shows WAXS results for $\mathrm{PET}_{64} \mathrm{Poly}(1,6 \mathrm{HD})_{36}$ and $\mathrm{PET}_{34} \mathrm{Poly}(1,6 \mathrm{HD})_{66}$, where the appearance of reflections corresponding to neat PET and Poly $(1,6$ HD) homopolymers can be seen (Table 3). Regarding the PET component, it can be observed that the intensity of its reflections is larger in Figure $5 a$ vs. Figure $5 b$, suggesting that when poly $(1,6 \mathrm{HD})$ content increases, the amount of PET crystals in the copolymer decreases as expected. On the poly $(1,6 \mathrm{HD})$ side, the opposite effect occurs. Therefore, as expected, depending on the PET/poly(1,6 HD) composition, the intensity of the reflections of both components in the copolymer will be more or less appreciated, considering that both components affect the crystallinity values. This behavior is appreciated in the WAXS diffractograms for the entire series of copolymers formed by PET and poly $(1,6 \mathrm{HD})$ and shown in the Supporting Information. 


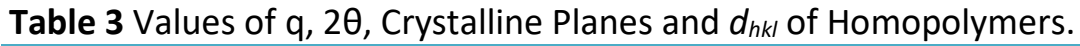

\begin{tabular}{|ccccc|}
$\begin{array}{c}\text { Crystalline Reflections } \\
\text { PET }\end{array}$ & $\mathbf{q}\left(\mathbf{n m}^{-1}\right)$ & $\mathbf{2 \theta}$ & Planes & $\boldsymbol{d}_{\mathbf{h k}}(\mathbf{n m})$ \\
\hline $\mathbf{1}$ & 11.63 & 10.94 & 011 & 0.540 \\
\hline $\mathbf{2}$ & 12.59 & 11.84 & 010 & 0.499 \\
\hline $\mathbf{3}$ & 15.36 & 14.47 & 111 & 0.409 \\
\hline $\mathbf{4}$ & 16.18 & 15.24 & 110 & 0.388 \\
\hline $\mathbf{5}$ & 18.51 & 17.46 & 100 & 0.339 \\
\hline $\mathbf{6}$ & 19.84 & 18.71 & 111 & 0.317 \\
\hline $\mathbf{7}$ & 23.02 & 21.75 & 111 & 0.273 \\
\hline $\mathbf{8}$ & 29.68 & 28.16 & 105 & 0.212 \\
\hline Poly(1,6 HD) & & & & \\
\hline $\mathbf{9}$ & 14.01 & 13.19 & 020 & 0.449 \\
\hline $\mathbf{1 0}$ & 17.04 & 16.06 & 110 & 0.369 \\
\hline
\end{tabular}
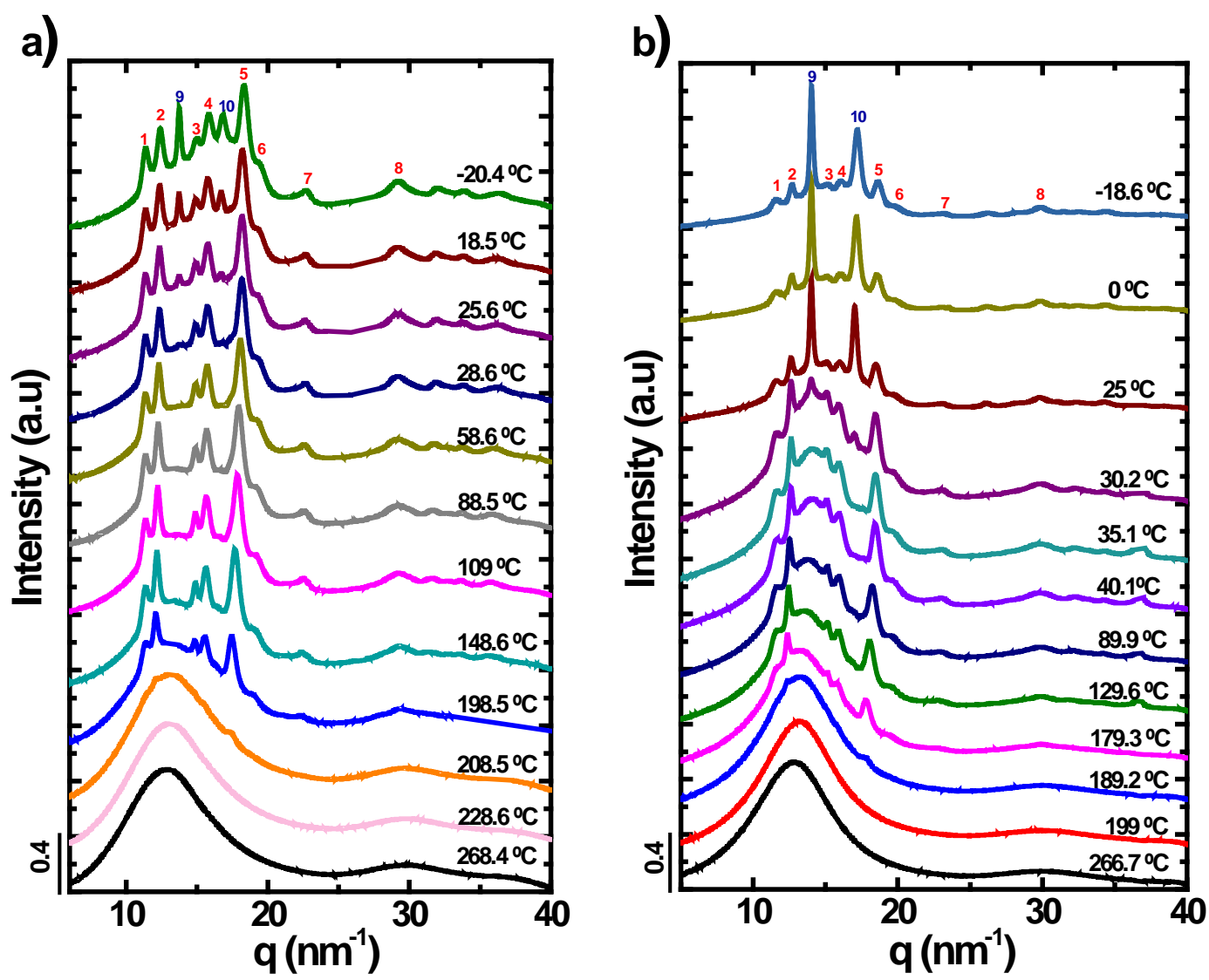

Figure 5. Real time synchrotron WAXS diffraction patterns for samples (a) $\mathrm{PET}_{64} \mathrm{Poly}(1,6 \mathrm{HD})_{36}$ and (b) PET ${ }_{34}$ Poly $(1,6 \mathrm{HD})_{66}$, cooled from the $270{ }^{\circ} \mathrm{C}$ to $-20^{\circ} \mathrm{C}$ at $20^{\circ} \mathrm{C} / \mathrm{min}$.

When the temperature is above the melting point of both components, a bimodal amorphous halo can be observed for both copolymers in Figure 5. This Figure 
also shows the gradual appearance of both PET and poly $(1,6 \mathrm{HD})$ reflections as the samples are cooled from the melt, depending on the crystallization temperature of each of the materials. PET reflections are the first to appear from the melt and down to $35^{\circ} \mathrm{C}$ approximately. It was found that the polyether begins to show its reflections in the diffractogram at a temperature of $29^{\circ} \mathrm{C}\left(T_{c}\right)$ for the copolymer in Figure $5 \mathrm{a}$. In the case of the copolymer shown in Figure $5 \mathrm{~b}$, it is from a temperature of $32{ }^{\circ} \mathrm{C}$ when reflections corresponding to the polyether are appreciated. In addition, the $T_{c}$ values obtained by WAXS are similar to those obtained by DSC.

Because the difference in $T_{c}$ between the components is large, the sequential appearance of PET and poly $(1,6 \mathrm{HD})$ reflections is clearly visible.

In summary, WAXS experiments show that the crystalline structure of the copolymers exhibits two types of unit cells: the triclinic unit cell corresponding to PET and the monoclinic unit cell corresponding to poly $(1,6 \mathrm{HD})$, corroborating the presence of both types of crystals in the copolymer, which had already been shown by DSC.

To study the lamellar periodicity (long period) of the PET-mb-Poly(1,6 HD) copolymers, as well as their lamellar thickness, SAXS experiments were carried simultaneously at the synchrotron source, while the WAXS were being measured. 

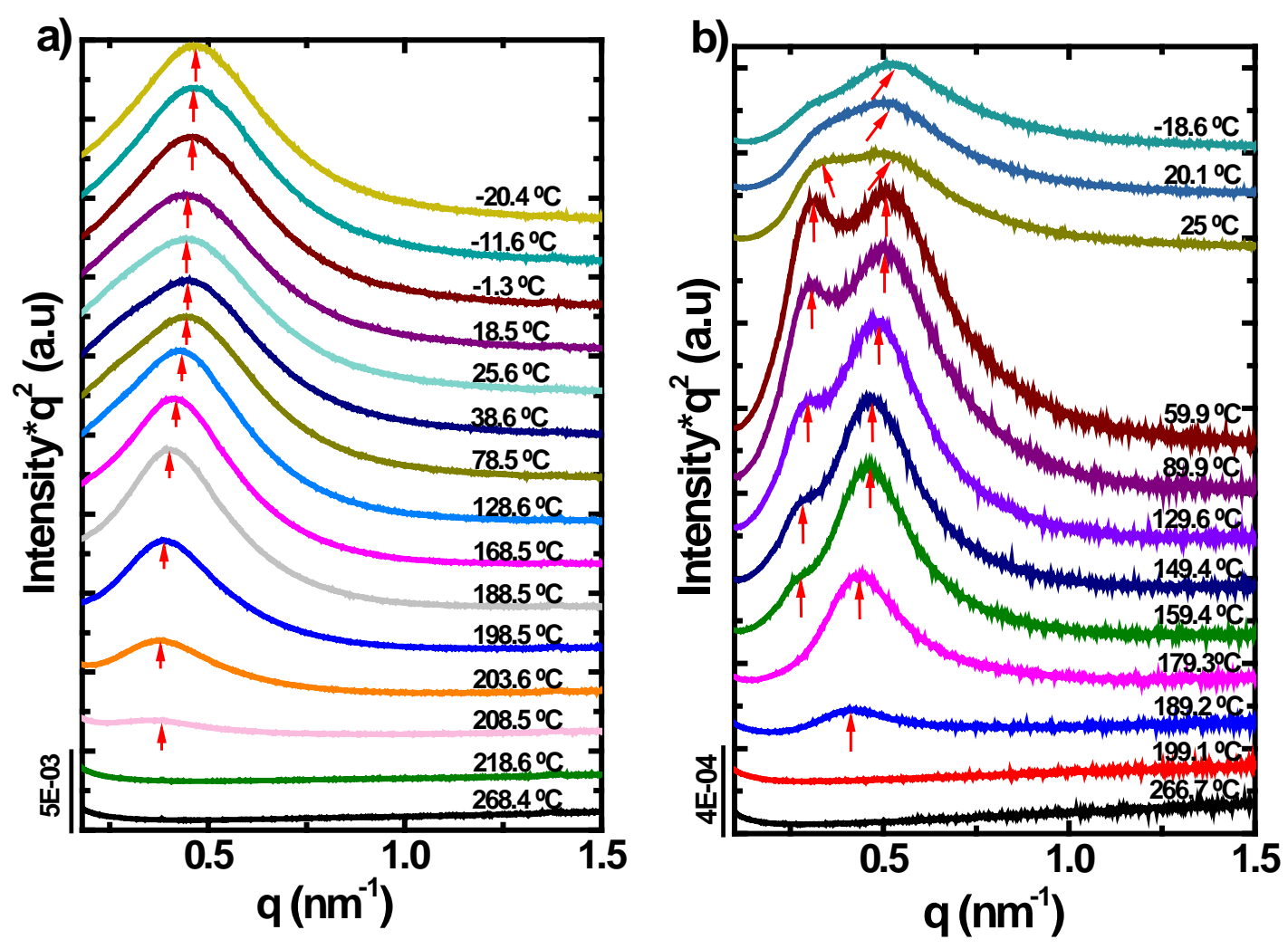

Figure 6. Lorentz-corrected SAXS profiles for (a) $\mathrm{PET}_{64} \mathrm{Poly}(1,6 \mathrm{HD})_{36}$ and (b) $\mathrm{PET}_{34} \mathrm{Poly}(1,6 \mathrm{HD})_{66}$, with intensity as a function of scattering vector. Data were taken of samples cooled from the $270{ }^{\circ} \mathrm{C}$ to $-20^{\circ} \mathrm{C}$ at $20^{\circ} \mathrm{C} / \mathrm{min}$.

Figure 6 shows selected SAXS results during cooling runs at $20^{\circ} \mathrm{C} / \mathrm{min}$ at different temperatures for (a) $\operatorname{PET}_{64} \operatorname{Poly}(1,6 \mathrm{HD})_{36}$ and (b) $\mathrm{PET}_{34} \mathrm{Poly}(1,6 \mathrm{HD})_{66}$ samples. Differences can be observed between both compositions. The first important result that can be appreciated in Figure 6 is that both copolymers exhibit no scattering peaks in the melt. This fact clearly indicates that the copolymers form a single phase in the melt. A similar result was found for all copolymers.

When PET ${ }_{64} \mathrm{Poly}(1,6 \mathrm{HD})_{36}$ is cooled from the melt (Figure 6a), and the PET component starts to crystallize at $208.5^{\circ} \mathrm{C}$, it starts to develop a maximum in SAXS. Below $203^{\circ} \mathrm{C}$, clear intense maxima can be observed due to the scattering caused by the periodic lamellar stacks of the PET component (i.e., long period). At much lower 
temperatures (at around room temperature), when both components have crystallized, this SAXS peak represents the average scattering from both PET and poly $(1,6$ HD) crystalline lamellae. The above can also be corroborated by reviewing the SAXS and WAXS results of the homopolymers (see Supporting Information, Figures S2, S3, S8, and S9).

On the other hand, in Figure 6b, two SAXS peaks can be observed for the poly $(1,6$ $\mathrm{HD})$ rich copolymer ( $\left.\mathrm{PET}_{34} \mathrm{Poly}(1,6 \mathrm{HD})_{66}\right)$, which do not correspond to two diffraction orders (as they are not located at $q$ values which are twice each other, as for first and second-order). It is important to note that the two SAXS peaks are seen first at $159.4{ }^{\circ} \mathrm{C}$ (Figure 6b) and become more intense in a temperature range were the polyether phase is in the melt (examples of double-peaked SAXS curves are provided in Figure $6 \mathrm{~b}$ in the range of $159-60^{\circ} \mathrm{C}$ approximately). The polyether phase, only crystallizes at much lower temperatures (around $30^{\circ} \mathrm{C}$ ), as demonstrated by both DSC (Figure 3a) and WAXS (Figure 5b).

This copolymer, $\mathrm{PET}_{34} \mathrm{Poly}(1,6 \mathrm{HD})_{66}$, crystallizes from a single-phase melt. But upon the crystallization of the PET phase, phase segregation occurs. Not only PET chains pack in their corresponding crystalline lamellae, triggering phase separation, but the amorphous phase also segregates into a PET-rich phase and a polyether-rich phase. We came to this conclusion after determining by both FlashDSC experiments and DMTA experiments that this copolymer exhibits two $T_{g}$ values (see results below). Therefore, we speculate that the two SAXS peaks in Figure $6 \mathrm{~b}$ are due to the $\mathrm{X}$-ray diffraction from the PET lamellar crystals plus the diffraction from the segregated interlamellar 
amorphous regions, as they occur at temperatures well above the crystallization of the polyether phase (which only crystallizes at $30^{\circ} \mathrm{C}$ ).

The exact interlamellar arrangement of the phase-separated amorphous regions is unknown, but it must be stacked in a way that produces a SAXS signal. A more indepth scattering study (including modeling of the SAXS data) would be needed to ascertain the exact origin of the two SAXS peaks observed and the reasons why they are only clearly seen at this composition. Figure S11 in the Supplementary Information shows that for copolymer $\mathrm{PET}_{61} \mathrm{Poly}(1,6 \mathrm{HD})_{39}$, a low- $q$ shoulder can also be observed for some high temperatures (i.e., 148.3 and $108.3^{\circ} \mathrm{C}$ ), but it is not very significant.

More information on WAXS and SAXS for different copolymers is given in the Supporting Information.

Block copolymer segregation is classified into three regimes: weak, intermediate and strong. There is no well-defined criterion to separate these regimes, however there are works that discuss this issue. The results reported by Matsen and Bates, indicate that $\chi N \leq 10$ represents a copolymer without phase segregation, when $\chi N \approx 12$ indicates the beginning of a weak to intermediate segregation and a value of $\chi N \approx 50$ indicates the beginning of a segregation from intermediate to strong. ${ }^{28,29}$

The segregation strength that could exist between PET and poly $(1,6 \mathrm{HD})$ was calculated $(\chi N)$ as a first approximation. First, the Flory-Huggins interaction parameter $(\chi)$ between PET and poly(1,6 HD) was determined using the equation described in the SI section and we obtained a value of $\chi=0.42 .^{30}$

The value of $N$ (total degree of polymerization) was calculated by Equation 2: 


$$
N=\frac{\left(M n_{A} * \Phi_{A}\right)+\left(M n_{B} * \Phi_{B}\right)}{\left(M n r_{A} * \Phi_{A}\right)+\left(M n r_{B} * \Phi_{B}\right)}
$$

where $M n_{A}$ is the molecular weight of the PET block, $M n_{B}$ is the molecular weight of the poly $(1,6 \mathrm{HD})$ block $(3,468 \mathrm{~g} / \mathrm{mol}), \Phi_{A}$ and $\Phi_{B}$ are the molar fractions of PET and poly $(1,6 \mathrm{HD})$ respectively, present in the copolymer. $M n r_{A}$ is the molecular weight of the repetitive unit of PET $(192 \mathrm{~g} / \mathrm{mol})$ and $M n r_{B}$ is the molecular weight of the repetitive unit of poly $(1,6 \mathrm{HD})(100 \mathrm{~g} / \mathrm{mol})$. The values of $N$ were calculated for every copolymer and the results are shown in Table 4.

Table 4 Molecular weights, $N$ and $\chi N$ of Copolymers.

\begin{tabular}{cccc}
\hline Sample & $\begin{array}{c}\mathrm{Mn}^{a}(\mathrm{~g} / \mathrm{mol}) \\
\text { PET block }\end{array}$ & $N$ & $\chi N$ \\
\hline PET $_{68}$ Poly(1,6 HD) $)_{32}$ & 7411 & 36 & 15.1 \\
PET $_{64}$ Poly(1,6 HD) $)_{36}$ & 6413 & 34 & 14.4 \\
PET $_{61}$ Poly(1,6 HD) $)_{39}$ & 5549 & 33 & 13.9 \\
PET $_{34}$ Poly(1,6 HD $)_{66}$ & 1997 & 32 & 13.5 \\
\hline${ }^{a}$ Calculated by $M n=(L \text { LEG from Table } 1)^{*}(192 \mathrm{~g} / \mathrm{mol})$ &
\end{tabular}

The segregation strength $(\chi N)$ between PET and poly(1,6 HD) was calculated multiplying $\chi$ by $N$. The results are appreciated in Table 4. In a linear AB diblock copolymer, $(\chi N)$ is the parameter that controls the segregation between blocks $A$ and $B$.

For all copolymers, the $\chi N$ values are below 50 which indicate a weak to intermediate segregation strength in these systems, tending more to weak segregation, because the values of $\chi N$ are closer to 12 . This means that a miscible or weakly segregated state in the melt would be predicted for a PET- $b$-Poly $(1,6 \mathrm{HD})$ diblock copolymer. As the polymers prepared here are multiblock copolymers, the presence of multiple covalent bonds between PET and poly $(1,6 \mathrm{HD})$ will increase the miscibility of 
the system. So, it is reasonable to assume that in the melt state, these multiblock copolymers should be in a single phase, as already demonstrated by SAXS experiments.

The $T_{g}$ of the segments (PET and polyether) that form the copolymer is usually a characteristic parameter for evaluating microphase separation. ${ }^{10,14}$ For instance, it has been reported that in PET copolymer systems with PEG, the $T_{g}$ value of the PEG present in the copolymer is usually higher than that of neat PEG. This result is related to the existence of a mixed amorphous phase containing both segments (PEG and noncrystallized segments of PET), where the PET segments reinforce the soft phase and increase the $T_{g}$ of the PEG. ${ }^{5}$

Analyzing the effect of the polyether component on the $T_{g}$ of the PET component for copolymers of PET and PEG, it was reported that the motion of PEG chains in the rubbery state could significantly influence the $T_{g}$ of PET, decreasing it in the copolymer, in comparison with the $T_{g}$ of neat PET. ${ }^{12,31}$

Table 5. Glass Transition Temperature of the PET-mb-Poly(1,6 HD).

\begin{tabular}{|c|c|c|c|c|}
\hline & \multicolumn{2}{|c|}{ DMTA } & \multicolumn{2}{|c|}{ FlashDSC } \\
\hline & PET & Poly $(1,6$ HD) & PET & Poly $(1,6$ HD $)$ \\
\hline & $T_{g}\left({ }^{\circ} \mathrm{C}\right)$ & $T_{g}\left({ }^{\circ} \mathrm{C}\right)$ & $T_{g}\left({ }^{\circ} \mathrm{C}\right)$ & $T_{g}\left({ }^{\circ} \mathrm{C}\right)$ \\
\hline PET & 106 & --- & 104 & --- \\
\hline $\operatorname{PET}_{68}$ Poly $(1,6 \text { HD })_{32}$ & 92.4 & a & 91.9 & -31.5 \\
\hline $\operatorname{PET}_{64}$ Poly $(1,6 \text { HD })_{36}$ & 59 & -7 & $\mathrm{~b}$ & $\mathrm{~b}$ \\
\hline PET $_{61}$ Poly $(1,6 \text { HD) })_{39}$ & 56 & -41 & $\mathrm{~b}$ & $\mathrm{~b}$ \\
\hline $\operatorname{PET}_{34}$ Poly $(1,6$ HD) 66 & 44.5 & -44 & 37.9 & -52.8 \\
\hline Poly(1,6 HD) & --- & -40 & --- & -59.6 \\
\hline
\end{tabular}

a: value not detected; b: these samples were not measured by FlashDSC.

The $T_{g}$ values of all samples were determined by DMTA (Table 5). Figure S13 (Supporting Information) shows that some PET-mb-Poly(1,6 HD) copolymers exhibit two $T_{g}$ values corresponding to a PET rich phase and a poly $(1,6 \mathrm{HD})$ rich phase. The $T_{g}$ values 
corresponding to the PET rich phase tend to decrease as the poly $(1,6 \mathrm{HD})$ content increases and are all lower than those of neat PET. This indicates that a PET rich phase is formed, where a small amount of poly $(1,6 \mathrm{HD})$ chains are dissolved in PET and therefore plasticize and depress the $T_{g}$ value. On the poly $(1,6 \mathrm{HD})$ composition side, the $T_{g}$ of the poly $(1,6 \mathrm{HD})$ in the copolymer tends to increase when the amount of PET increases, at least for some of the values, also indicating the formation of a poly $(1,6 \mathrm{HD})$ rich phase that contains a small amount of PET chains. Similar results were obtained using ultra-fast DSC (Figure 7 \& Figure S14, SI). In both cases it can be seen that the two copolymers $\left[\mathrm{PET}_{68} \mathrm{Poly}(1,6 \mathrm{HD})_{32}\right.$ and $\mathrm{PET}_{34} \mathrm{Poly}(1,6 \mathrm{HD})_{66}$ ] show two $T_{g}$ values, suggesting that there is a microphase separation in these copolymers amorphous phase, possibly triggered by the crystallization of the PET component (see Figure 6b).

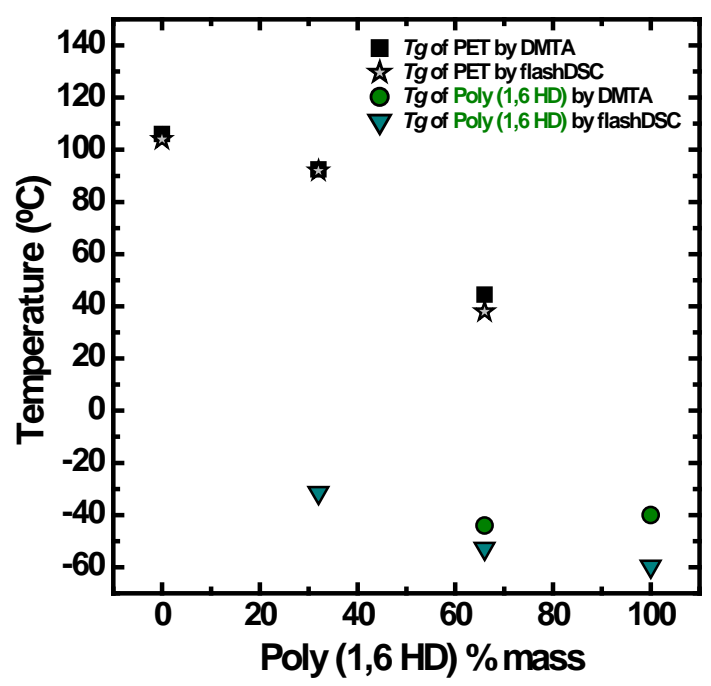

Figure 7. $T_{g}$ values of some copolymers $\mathrm{PET}_{\mathrm{x}} \mathrm{Poly}(1,6 \mathrm{HD})_{\mathrm{y}}$ as a function of poly $(1,6 \mathrm{HD})$ content in the copolymer. The data reported include results from DMTA and FlashDSC.

\section{Isothermal Crystallization Kinetics}

First, the isothermal crystallization of neat PET and the PET component within the PET-mb-Poly(1,6 HD) copolymers of different compositions has been determined by 
DSC. As PET crystallizes at higher temperatures, it is easy to determine its crystallization kinetics in the copolymers, while the polyether component remains in the melt.

Figure $8 \mathrm{a}$ plots the inverse of the half crystallization time $\left(1 / \tau_{50 \%}\right)$, a quantity proportional to the overall crystallization rate (encompassing both nucleation and growth), versus the isothermal crystallization temperatures $\left(T_{c}\right)$ for neat PET and PET components within the copolymers. At the crystallization temperatures used to crystallize the PET component, the poly $(1,6 \mathrm{HD})$ chains are in the melt state (see protocol in Figure S16, SI).

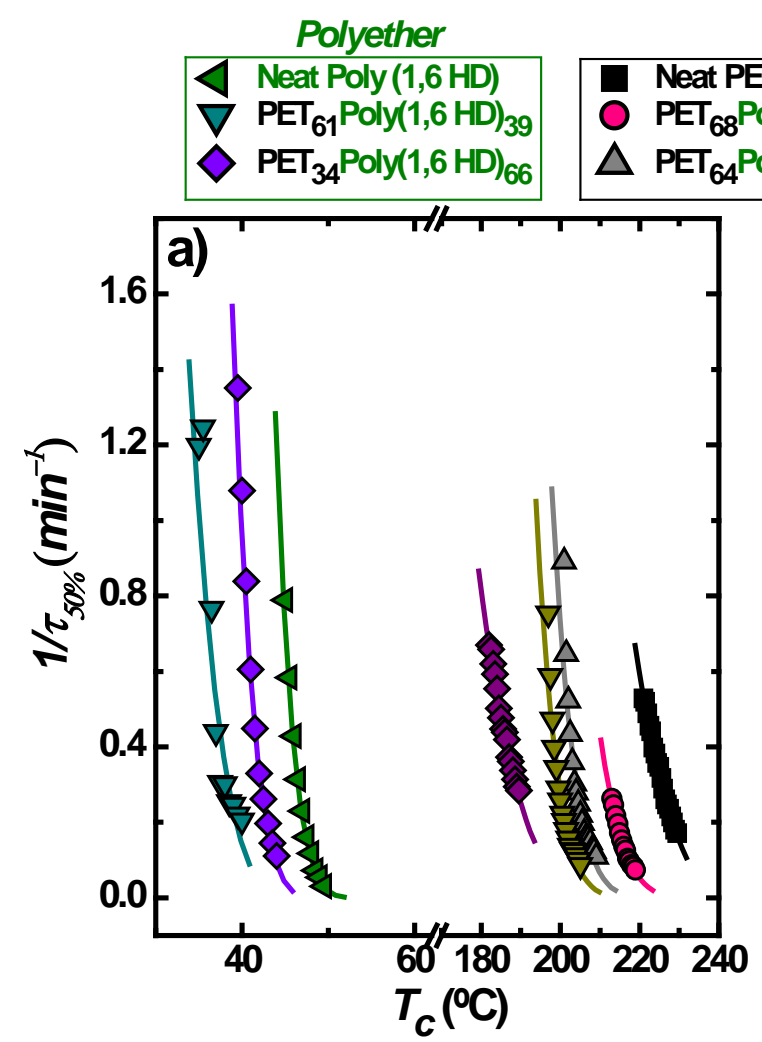

PET 
$\left(T_{m}{ }^{\circ}-T_{c}\right)$, for neat PET, neat poly $(1,6 \mathrm{HD})$ and for PET-mb-Poly $(1,6 \mathrm{HD})$ copolymers. The solid lines are fits to the Lauritzen and Hoffman theory (see below and Supplementary Information).

Figure 8a shows that neat PET crystallizes faster than the PET blocks present in the copolymers. Additionally, the crystallization rate decreases as the amount of poly $(1,6 \mathrm{HD})$ in the copolymer increases. It is expected that the equilibrium melting temperature of PET should decrease as poly $(1,6 \mathrm{HD})$ chains are incorporated in the multi-block copolymers, as these copolymers are miscible in the melt state, as evidenced by SAXS (see results above). We have estimated the values of $T_{m}{ }^{0}$ using the procedure explained in the Supporting Information. Using such values, Figure $8 a$ has been represented in Figure $8 \mathrm{~b}$ as a function of supercooling (i.e., $\Delta T=T_{m}{ }^{0}-T_{c}$ ). It can be appreciated that the curves as a function of supercooling are closer together (the range in terms of temperature interval is narrower as compared to the range in $T_{c}$ values), as the supercooling will normalize the plots by the thermodynamic differences between the copolymers, but some kinetic factors are still affecting the behavior. As the copolymers form a single phase in the melt, a plasticization effect could be expected from the polyether chains to enhance the PET-rich phase crystallization. However, the copolymer has a blocky structure, where the chains are tethered at both ends, and each covalent bond with a neighboring PET block is a defect that will difficult the crystallization of chain segments next to it. This chain tethering effect, plus the excess in chain mobility (which typically affect secondary nucleation by chain detachment at the growth front) of the polyether segments at the temperatures at which the PET phase starts to crystallize, may be responsible for the decrease in the overall crystallization rate of the PET phase within the copolymers. 
Figure $8 \mathrm{a}$ also shows the crystallization behavior of the poly $(1,6 \mathrm{HD})$ component present in the copolymers vs the pure poly $(1,6 \mathrm{HD})$. The crystallization rate of the poly $(1,6 \mathrm{HD})$ blocks in the copolymers is slower than that of the homopolymer and also when the amount of PET in the copolymer increases, the crystallization rate of the poly $(1,6 \mathrm{HD})$ chains decreases. The crystallization rate of the poly(1,6 HD) components in the copolymers was determined after a previous crystallization of the PET component, as explained in Figure S17 (Supporting Information). The previously formed PET crystals are probably restricting the crystallization of the poly $(1,6 \mathrm{HD})$ phase. The equilibrium melting temperature of poly $(1,6 \mathrm{HD})$ should also decrease as PET is incorporated in the copolymer chains (see Supporting Information). With experimental values of $T_{m}{ }^{0}$, the data in Figure $8 \mathrm{a}$ for the poly $(1,6 \mathrm{HD})$ component is also represented in Figure $8 \mathrm{~b}$ as a function of supercooling.

As the two components are miscible in the melt, PET chains crystallize from a homogeneous melt, forming spherulites that grow until impingement. The internal region of such spherulites contains PET lamellae plus interlamellar amorphous regions formed by molten poly(1,6 HD) chains covalently bonded with PET chains. Not all PET chains in the copolymers crystallize. In fact, only a minority since the crystallinity of the PET component decreases with poly $(1,6 \mathrm{HD})$ content in the copolymer, from around $45 \%$ down to $10 \%$, as shown in Figure 9. Inside the previously formed PET spherulitic templates is where the poly $(1,6 \mathrm{HD})$ blocks have to crystallize. In these interlamellar PET regions, the poly $(1,6 \mathrm{HD})$ chains will be confined, and their confinement will increase as PET increases in the copolymers (as well as the number of PET crystals), thereby restricting their crystallization ability. Similar behavior has been observed in melt miscible block and random copolymers. ${ }^{11,32,33}$ 


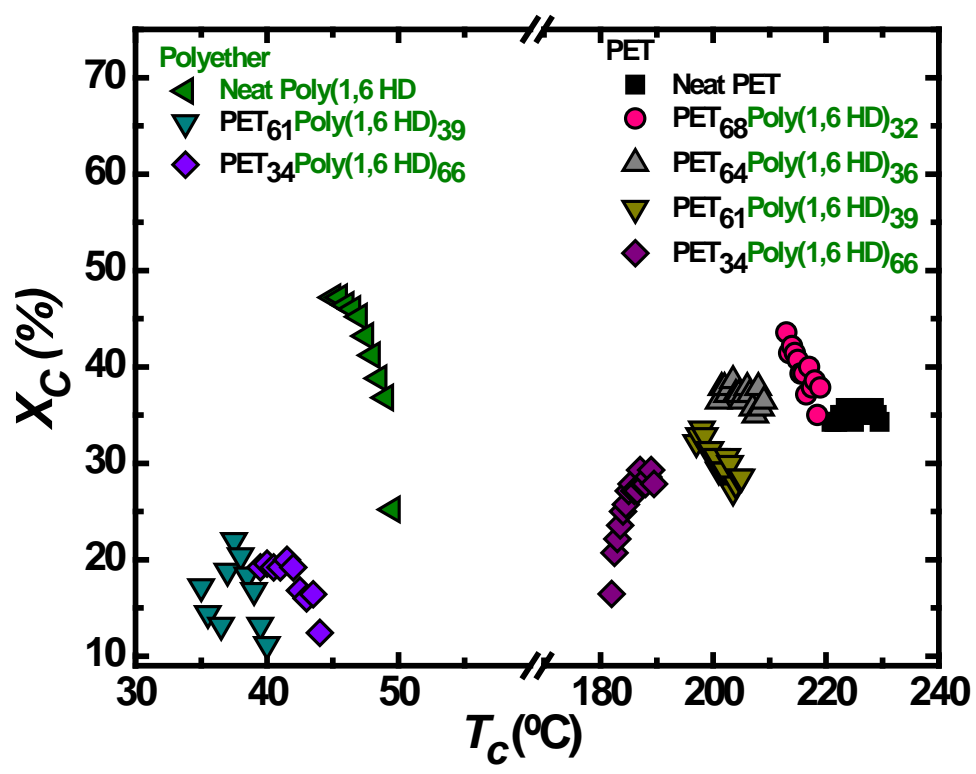

Figure 9. Percentage of crystallinity $\left(X_{c}\right)$, obtained after the crystallinity value has saturated during isothermal crystallization, as a function of crystallization temperature $\left(T_{c}\right)$ for PET-mbPoly(1,6 HD).

Figure 9 shows the crystallinity of each of the components (PET and poly(1,6 HD)) in the copolymer after the isothermal crystallization process has finished. Despite some fluctuations in the values, in general terms, the crystallinity is greatly reduced when the content of the component under consideration decreases within the copolymer.

The Avrami and the Lauritzen and Hoffman theories are usually employed to fit crystallization kinetics data (the equations of these theories are described in Supporting Information). 

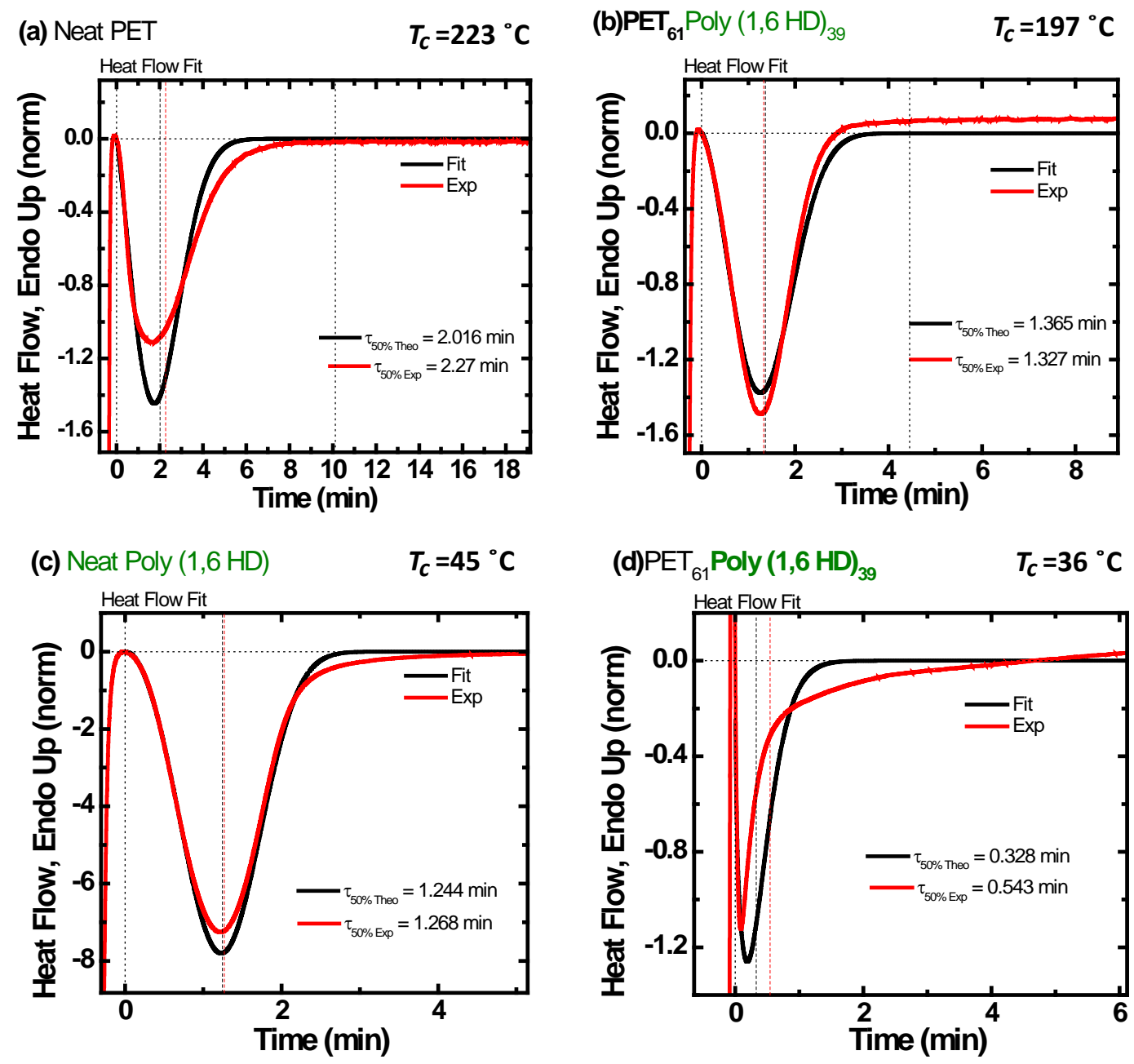

Figure 10. Experimental data compared with fits to the Avrami equation for $(a, b)$ neat PET and PET segment in PET $_{61}$ Poly $(1,6 \mathrm{HD})_{39}$, respectively. (c, d) neat poly $(1,6 \mathrm{HD})$ and poly(1,6 HD) segment in $\mathrm{PET}_{61}$ Poly $(1,6 \mathrm{HD})_{39}$, respectively.

The Avrami equation fits the primary crystallization range very well. Therefore, the fits should be done at low conversion values (3-20\%) to the semi-crystalline state. ${ }^{34}$ Comparing the DSC isothermal traces with predictions of the Avrami theory are shown in Figures 10a and 10b for neat PET and the PET component in the copolymer. The Avrami fit is excellent in the primary crystallization range (i.e., until the spherulites or axialites impinge on one another, a point in time similar to the peak value), as indicated by correlation coefficients of 1 (in the conversion range of $3-20 \%$ ), but also beyond $20 \%$, 
as experimental and fitted curves overlap with each other in Figures 10a and 10b until at least $50 \%$ conversion.

In the case of neat poly(1,6 HD), a good fit between the Avrami model and the experimental DSC data was also observed until at least 50\% conversion (Figure 10c). On the other hand, the Avrami equation seems to fit well only for the primary crystallization (3-20\% conversion) of the poly (1,6 HD) segment in the copolymer. Above $20 \%$, the fit between the Avrami model and the experimental data has certain deviations, which are shown in Figure $10 \mathrm{~d}$. These deviations could be produced because poly(1,6 HD) crystallizes inside PET spherulites and therefore it can only form lamellar crystals in between PET lamellae.

For both PET and poly(1,6 HD) present in the copolymers, parameters derived from isothermal crystallization were obtained. The values of $K^{1 / n}$ (a modified isothermal crystallization rate constant) are shown in Figure 11 a. $K$ has units of $n^{-1}$, i.e., its units depend on the Avrami index. To compare $K$ values with similar units, $K$ was elevated to the $1 / \mathrm{n}$ power. The overall crystallization rate that includes nucleation and growth is proportional to $K^{1 / n}$; therefore, as expected, its trend value with crystallization temperature is almost identical to that shown in Figure 8 a for $1 / \tau_{50 \%}$. 


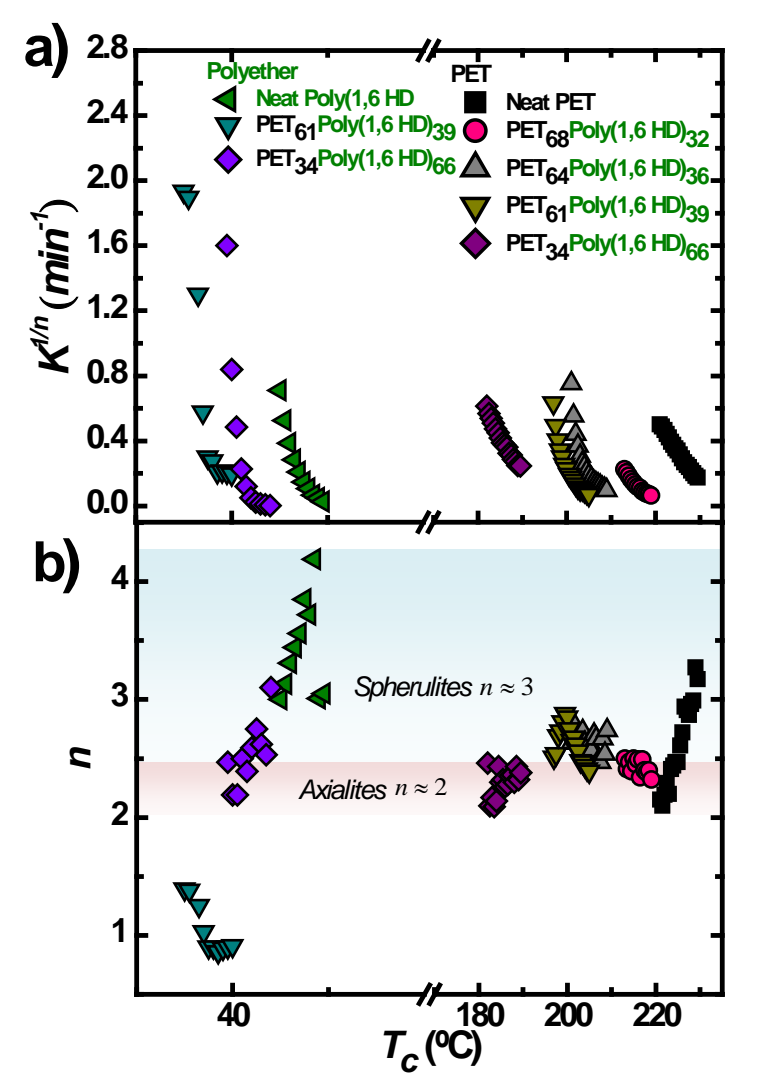

Figure 11. (a) Isothermal crystallization rate constant $\left(K^{1 / n}\right)$ as a function of crystallization temperature $\left(T_{c}\right)$ and (b) Avrami index $(n)$ as a function of isothermal crystallization temperature $\left(T_{c}\right)$, for PET-mb-Poly(1,6 HD).

The values of $n$ (i.e., Avrami index) for neat polymers (PET and poly(1,6 HD)) and for PET and poly $(1,6 \mathrm{HD})$ components in the copolymers are represented in Figure $11 \mathrm{~b}$ as a function of crystallization temperature. For neat PET, values from 2 to 3.2 were obtained. A value of $n=3$ (or $n$ in the range of 2.5-3.2, which can be approximated to 3 ) corresponds to instantaneously nucleated spherulites or sporadically nucleated axialites. Avrami index values of $\mathrm{n}=2$ correspond (for polymeric materials) to instantaneously nucleated axialites.

Figure $11 \mathrm{~b}$ also reports Avrami index values for neat poly(1,6 HD) and for the poly $(1,6 \mathrm{HD})$ blocks within the copolymers. Values between 3 and 4 were obtained for 
the neat poly $(1,6 \mathrm{HD})$, which correspond to instantaneously and sporadically nucleated spherulites respectively. On the other hand, a very interesting behavior has been found for the poly $(1,6 \mathrm{HD})$ phase of the two copolymers examined.

The Avrami index first decreases to 2 in the case of the copolymer with 34\% PET, indicating that only 2D crystals can be formed instantaneously within the previously crystallized PET superstructural aggregates (which correspond for this copolymer to axialites).

Then a dramatic reduction of the Avrami index is observed as $n$ values of 0.91 to 1.5 are obtained for the copolymer with 61\% PET. In this case, Avrami indexes of 1 or lower have been associated with confined crystallization in the minority phases of diblock copolymers and also in nanocomposites with very large amounts of nano-fillers. 35-38 The reason for this behavior is related to the difficulties experienced by confined materials to be nucleated. When this happens, the nucleation becomes the dominating (or slow step) in the overall crystallization kinetics, as growth tends to be much faster than nucleation. Therefore, the crystallization kinetics transforms into first-order kinetics dominated by nucleation. 


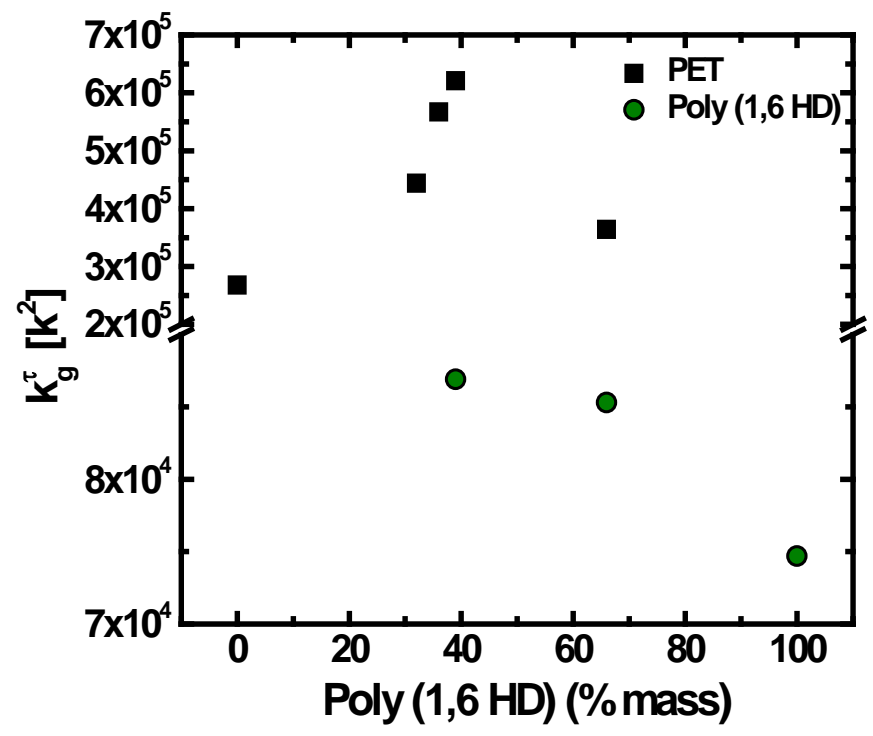

Figure 12. Values of $k_{g}^{\tau}$ derived from LH fitting plotted as a function of poly $(1,6 \mathrm{HD})$ content.

When DSC data is fitted with the Lauritzen and Hoffman theory, $G(T)$ in equation S10 (see Supplementary Information) is replaced by the inverse of the experimental overall half-crystallization time as the equation will predict overall crystallization rates (including both nucleation and growth). ${ }^{39}$ All solid lines that are represented on top of the experimental data in Figure 8 are fits to the Lauritzen and Hoffman theory. Figure 8a shows excellent fits (in the temperature range represented) to the experimental DSC kinetics data to the LH theory (solid lines). The parameter $K_{g}$ is equal to $K_{g}^{\tau}$ when DSC data is used, and it is proportional to the overall energy barrier for crystallization (including primary nucleation and growth). The values of $T_{m}^{0}$ were obtained as indicted in the Supplementary Information.

Figure 12 shows how $K_{g}^{\tau}$ depends on copolymer composition. Comparing the two homopolymers, as poly $(1,6 \mathrm{HD})$ is a more flexible polymer than $\mathrm{PET}$, that crystallizes much faster (see Figure 8), the $K_{g}^{\tau}$ value is much lower, as expected as it is proportional to the energy barrier for nucleation and growth. 
If we now consider the poly $(1,6 \mathrm{HD})$ component case, when the amount of poly(1,6 HD) increases in the copolymer, $K_{g}^{\tau}$ decreases. This result shows that the energy barrier for nucleation and growth decreases as the confinement inflicted by the PET previous crystallization decreases. For the PET component, the energy barrier seems to be larger in all copolymers versus neat PET, which indicates that the molten poly $(1,6$ HD) component also difficults PET crystallization, as already evidenced by the PET component reduced crystallization rate as poly $(1,6 \mathrm{HD})$ content in the copolymer increases. These energy barrier trends are consistent with both isothermal crystallization kinetics and non-isothermal crystallization of the copolymers since the crystallization of each component within the copolymer is always slower and more difficult than for the neat components.

\section{Morphology}

The materials obtained were analyzed by Polarized Light Optical Microscopy (PLOM) and Atomic Force Microscopy (AFM). Figure 13 shows that PET samples exhibit a micro-spherulitic morphology, independent of the degree of supercooling. 


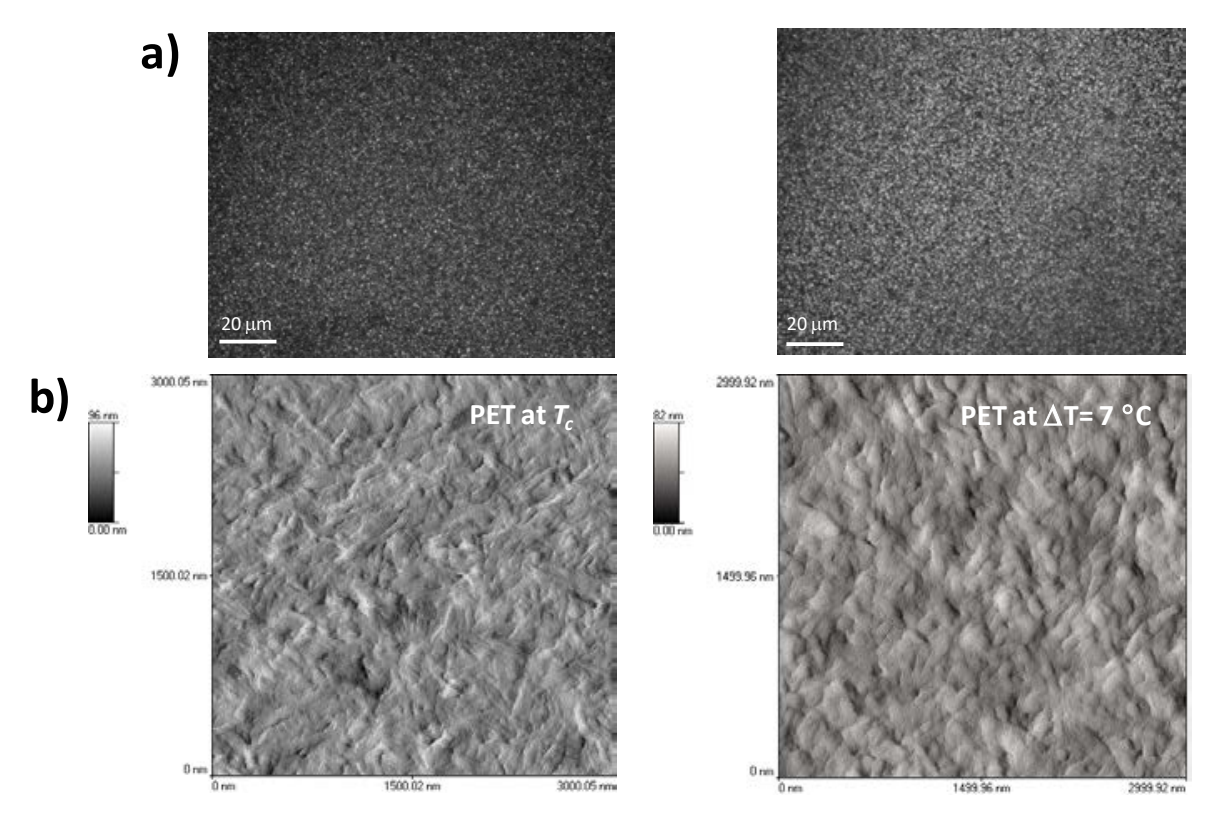

Figure 13. Morphological details of PET sample crystalized at $T_{c}$ (left) and $\Delta T=7^{\circ} \mathrm{C}$ (right) by optical microscopy (a) and AFM (b).

On the contrary, the poly(1,6 HD) samples in Figure 14 show a clear axialitic morphology. In Figure 15, the morphological aspects of the copolymer samples PET-mbPoly(1,6 H,D), with variable PET/poly(1,6 HD) content ratio can be observed. Neither PLOM nor AFM shows any differences in copolymer samples morphology with different poly $(1,6 \mathrm{HD})$ content. 
a)

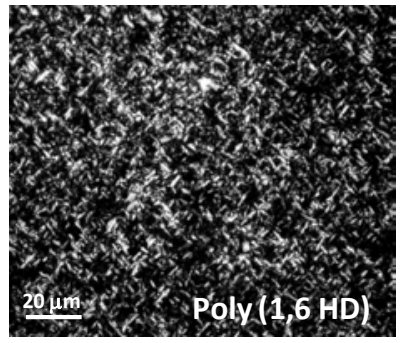

b)

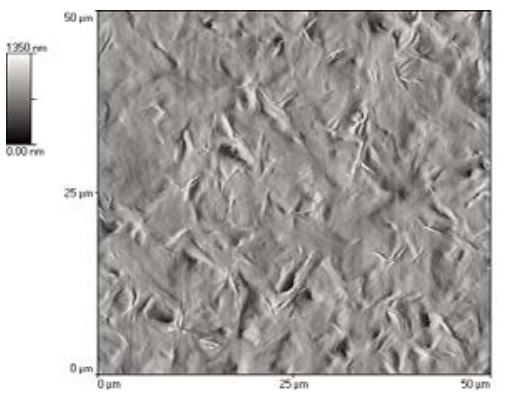

Figure 14. Morphological details of poly $(1,6 \mathrm{HD})$ sample quenched at room temperature by optical microscopy (a) and AFM (b). 

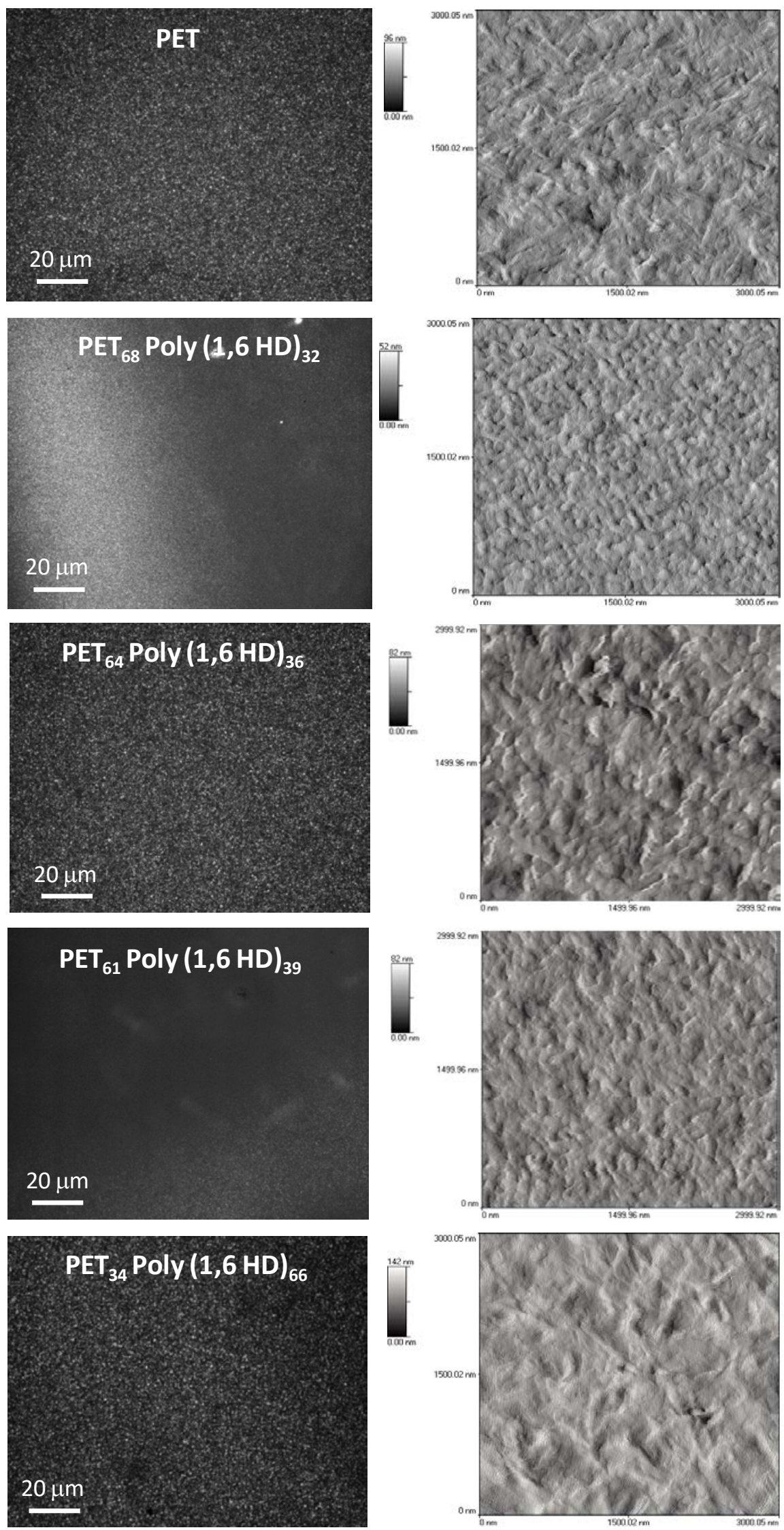

Figure 15. Morphological details of copolymer PET-mb-Poly(1,6 HD) samples crystalized at $T_{c}$ : optical microscopy (left) and AFM (right). 


\section{Single phase melt}

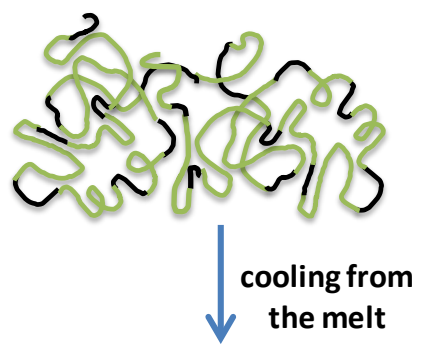

\section{PET phase crystallizes}
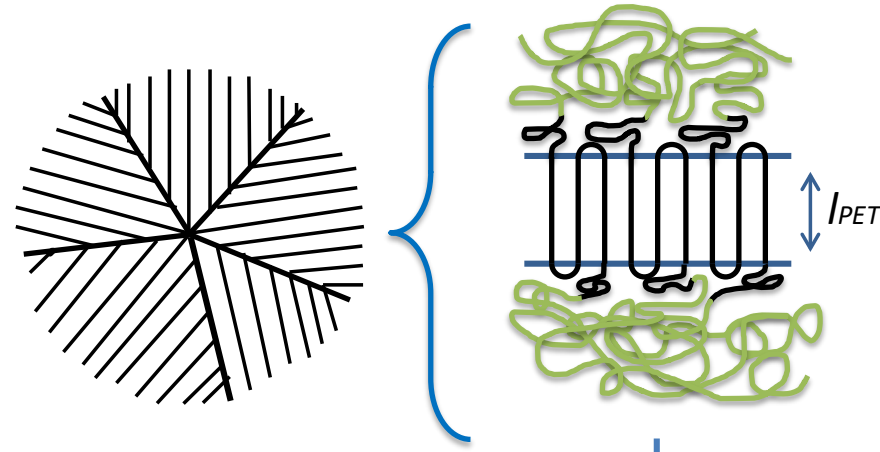

further cooling

\section{PET and Polyether crystals coexist}

and the amorphous phases are separated (PET rich and Polyether rich amorphous phases)
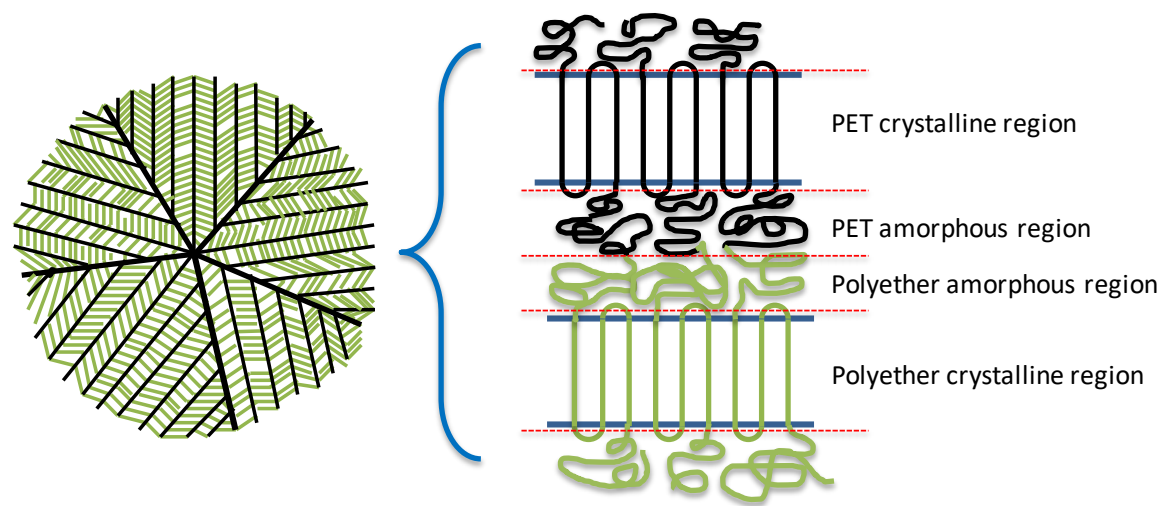

Scheme 2. A schematic drawing of the formation of the PET- $m b$-Poly $(1,6 \mathrm{HD})$. PET molecules or lamellae are represented in black while those of Poly $(1,6 \mathrm{HD})$ are drawn in green.

In summary, similar morphological features have been found for all copolymer samples prepared at the different thermal conditions regardless of the amount of poly $(1,6 \mathrm{HD})$ in the copolymers. All copolymer samples showed a micro-spherulitic 
morphology completely dominated by PET, even for the compositions rich in poly $(1,6$ $H D$ ). As the PET component is the first to crystallize from a homogeneous melt, it forms micron size spherulitic templates (filled with molten PET chains and poly $(1,6 \mathrm{HD})$ chains) that grow until impingement with one another. Because the size of the spherulitic templates is so small, it is very difficult to observe differences, as the dominant feature is the external "skeleton" or micro-spherulitic templates.

Considering all the results shown in this paper, Scheme 2 shows an approximate description of how the semi-crystalline structure develops in these multi-block copolymers. Scheme 2 is a simplified scheme that is not intended to explain in detail the results of all copolymers, but more their general common behavior.

Scheme 2 (first cartoon at the top) represents how both PET and poly(1,6 HD) chain segments within the multi-block copolymer form a single-phase melt state, as demonstrated by SAXS.

Subsequently (Scheme 2, middle cartoon), the copolymer is cooled to a temperature at which only PET segments can crystallize forming lamellae (whose periodicity was determined by SAXS) arranged in spherulitic templates. During the crystallization of the PET component, phase separation of amorphous PET and poly $(1,6$ HD) chains is triggered (the cartoon shows a complete phase separation of amorphous phases for simplicity, but in fact, the two amorphous phases are not completely segregated, they are formed by one PET-rich phase and a polyether rich phase, as indicated by the composition-dependent $T_{g}$ values).

Upon further cooling (Scheme 2, bottom cartoon), the poly(1,6 HD) chain segments (represented in green color) crystallize inside the previously formed PET 
spherulites (with lamellae represented with black lines). After crystallization, the amorphous regions of both components are phase-separated, as already mentioned, as two $T_{g}$ s are detected by DMTA and FlashDSC measurements. Hence, four distinct phases can be identified (two crystalline and two amorphous phases) plus their respective interphases, giving these double crystalline copolymers a particularly rich morphology evolved from self-assembly during cooling from a single-phase melt.

\section{Conclusions}

A series of new PET- $m b$-Poly $(1,6 \mathrm{HD})$ copolymers were synthesized in bulk using organocatalysis. ${ }^{1} \mathrm{H}$ and ${ }^{13} \mathrm{C}$ NMR confirmed the copolymerization and the random character of the copolymers. The materials showed that both components in the copolymer (PET and poly(1,6 HD)) can crystallize giving rise to a double crystalline polymeric material. The thermal properties of the copolymers were strongly affected by the PET/poly(1,6 HD) composition, resulting in multiblock copolymers with different crystallinities and different ranges of glass transition temperatures. The crystallization rate of each of the components in the copolymer was largely dependent on PET/poly $(1,6$ HD) composition.

The copolymers exhibit a very complex superstructural self-assembly as a function of temperature. They form a single-phase melt as evidenced by SAXS. Upon cooling from the melt, the PET component forms spherulitic superstructural templates, inside which phase segregation of the amorphous PET and molten poly $(1,6 \mathrm{HD})$ is triggered. Further cooling causes the crystallization of the poly $(1,6 \mathrm{HD})$ chains inside the 
PET spherulitic templates creating a double crystalline material with coexisting 4 phases (two crystalline and two amorphous phases) plus their respective interphases.

It should be noted that a micro-spherulitic morphology was found for all copolymer samples regardless poly $(1,6 \mathrm{HD})$ content present in the copolymers, as the PET component is the first to crystallize from a mixed melt forming micro-spherulitic templates that totally dominate the resulting morphology.

\section{Acknowledgments}

We acknowledge funding by the European Union's Horizon 2020 research and innovation programme under the Marie Sklodowska-Curie grant agreement No 778092. We also acknowledge funding by MINECO through project MAT2017-83014-C2-1-P. Irma Flores would like to acknowledge CONACYT (Mexico) for the Ph.D. grant awarded. We also acknowledge the contribution of Ms. Sofía Guezala for her help with the NMR measurements and Dr. Itxaso Calafel for her help with the DMTA measurements.

\section{ASSOCIATED CONTENT}

DSC, WAXS, SAXS data among other and various calculations are presented in the Supplementary Information. 


\section{References}

(1) Parthiban, A. Trends in Synthetic Strategies for Making (CO)Polymers. In Synthesis and Applications of Copolymers; John Wiley \& Sons, Inc.: Hoboken, NJ, USA, 2014; pp 1-28. https://doi.org/10.1002/9781118860168.ch1.

(2) Sousa, A. F.; Vilela, C.; Matos, M.; Freire, C. S. R.; Silvestre, A. J. D.; Coelho, J. F. J. Polyethylene Terephthalate: Copolyesters, Composites, and Renewable Alternatives. In Poly(Ethylene Terephthalate) Based Blends, Composites and Nanocomposites; Elsevier, 2015; pp 113-141. https://doi.org/10.1016/B978-0323-31306-3.00007-5.

(3) Ma, D.; Wang, M.; Wang, M.; Zhang, X.; Luo, X. Compositional Heterogeneity, Thermostable, and Shape Memory Properties of Ethylene Oxide-Ethylene Terephthalate Segmented Copolymer with Long Soft Segment. J. Appl. Polym. Sci. 1998, $69 \quad$ (5), $\quad 947-955 . \quad$ https://doi.org/10.1002/(SICI)10974628(19980801)69:5<947::AID-APP14>3.0.CO;2-L.

(4) Huang, W.; Wan, Y.; Chen, J.; Xu, Q.; Li, X.; Yang, X.; Li, Y.; Tu, Y. One Pot Synthesis and Characterization of Novel Poly(Ether Ester) Mutiblock Copolymers Containing Poly(Tetramethylene Oxide) and Poly(Ethylene Terephthalate). Polym Chem 2014, 5 (3), 945-954. https://doi.org/10.1039/C3PY00932G.

(5) Wang, M.; Zhang, L.; Ma, D. Degree of Microphase Separation in Segmented Copolymers Based on Poly(Ethylene Oxide) and Poly(Ethylene Terephthalate). Eur. Polym. J. 1999, 35 (7), 1335-1343. https://doi.org/10.1016/S0014-3057(99)000300.

(6) Li, W.; Kong, X.; Zhou, E.; Ma, D. Isothermal Crystallization Kinetics of Poly(Ethylene Terephthalate)-Poly(Ethylene Oxide) Segmented Copolymer with Two Crystallizing 
Blocks. Polymer 2005, $46 \quad$ (25), 11655-11663.

https://doi.org/10.1016/j.polymer.2005.09.067.

(7) Kong, X.; Yang, X.; Zhou, E.; Ma, D. Nonisothermal Crystallization Kinetics of Ethylene Terephthalate-Ethylene Oxide Segmented Copolymers with Two Crystallizing Segments. Eur. Polym. J. 2000, 36 (6), 1085-1090. https://doi.org/10.1016/S0014-3057(99)00186-X.

(8) Coleman, D. Block Copolymers: Copolymerization of Ethylene Terephthalate and Polyoxyethylene Glycols. J. Polym. Sci. 1954, 14 (73), 15-28. https://doi.org/10.1002/pol.1954.120147303.

(9) Hu, J.; Yu, H.; Chen, Y.; Zhu, M. Study on Phase-Change Characteristics of PET-PEG Copolymers. J. Macromol. Sci. Part B 2006, 45 (4), 615-621. https://doi.org/10.1080/00222340600770210.

(10) Qian, Z.; Li, S.; He, Y.; Liu, X. Synthesis and in Vitro Degradation Study of Poly(Ethylene Terephthalate)/Poly(Ethylene Glycol) (PET/PEG) Multiblock Copolymer. Polym. Degrad. Stab. 2004, 83 (1), 93-100. https://doi.org/10.1016/S0141-3910(03)00229-5.

(11) Kong, X.; Yang, X.; Li, G.; Zhao, X.; Zhou, E.; Ma, D. Nonisothermal Crystallization Kinetics: Poly(Ethylene Terephthalate)-Poly(Ethylene Oxide) Segmented Copolymer and Poly(Ethylene Oxide) Homopolymer. Eur. Polym. J. 2001, 37 (9), 1855-1862. https://doi.org/10.1016/S0014-3057(01)00046-5.

(12) Chun, B. C.; Cha, S. H.; Chung, Y.-C.; Cho, J. W. Enhanced Dynamic Mechanical and Shape-Memory Properties of a Poly(Ethylene Terephthalate)-Poly(Ethylene Glycol) Copolymer Crosslinked by Maleic Anhydride. J. Appl. Polym. Sci. 2002, 83 (1), 2737. https://doi.org/10.1002/app.2228. 
(13) Huang, M.; Zheng, L.; Wang, L.; Dong, X.; Gao, X.; Li, C.; Wang, D. Double Crystalline Multiblock Copolymers with Controlling Microstructure for High Shape Memory Fixity and Recovery. ACS Appl. Mater. Interfaces 2017, 9 (35), 30046-30055. https://doi.org/10.1021/acsami.7b08403.

(14) Deschamps, A. A.; Grijpma, D. W.; Feijen, J. Poly(Ethylene Oxide)/Poly(Butylene Terephthalate) Segmented Block Copolymers: The Effect of Copolymer Composition on Physical Properties and Degradation Behavior. Polymer 2001, 42 (23), 9335-9345. https://doi.org/10.1016/S0032-3861(01)00453-0.

(15) Dreyfuss, M. P.; Dreyfuss, P. A 'Living' Polymer after Cationic Iniation. Polymer $1965,6(2), 93-95$.

(16) Perry, S.; Hibbert, H. Studies on Reactions Relating to Carbohydrates and Polysaccharides. LXI. The Mechanism of Polimerization of Ethylene Oxideperry1940.Pdf. J Am Chem Soc 1940, 62 (10), 2599-2604.

(17) Vandenberg, E. J. Organometallic Catalysts for Polymerizing Monosubstituted Epoxides. J. Polym. Sci. 1960, $47 \quad$ (149), 486-489. https://doi.org/10.1002/pol.1960.1204714947.

(18) Basterretxea, A.; Gabirondo, E.; Jehanno, C.; Zhu, H.; Flores, I.; Müller, A. J.; Etxeberria, A.; Mecerreyes, D.; Coulembier, O.; Sardon, H. Polyether Synthesis by Bulk Self-Condensation of Diols Catalyzed by Non-Eutectic Acid-Base Organocatalysts. ACS Sustain. Chem. Eng. 2019, 7 (4), 4103-4111. https://doi.org/10.1021/acssuschemeng.8b05609.

(19) Basterretxea, A; Gabirondo, E.; Flores, I.; Etxeberria, A.; Gonzalez, A.; Müller, A. J.; Mecerreyes, D.; Coulembier, O.; Sardon, H. Isomorphic Polyoxyalkylene 
Copolyethers Obtained by Copolymerization of Aliphatic Diols. 2019, 52 (9), 35063515. 10. https://doi.org/10.1021/acs.macromol.9b00469.

(20) Flores, I.; Demarteau, J.; Müller, A. J.; Etxeberria, A.; Irusta, L.; Bergman, F.; Koning, C.; Sardon, H. Screening of Different Organocatalysts for the Sustainable Synthesis of PET. Eur. Polym. J. 2018, 104, 170-176. https://doi.org/10.1016/j.eurpolymj.2018.04.040.

(21) Coady, D. J.; Fukushima, K.; Horn, H. W.; Rice, J. E.; Hedrick, J. L. Catalytic Insights into Acid/Base Conjugates: Highly Selective Bifunctional Catalysts for the RingOpening Polymerization of Lactide. Chem. Commun. 2011, 47 (11), 3105-3107. https://doi.org/10.1039/c0cc03987j.

(22) Krevelen, D. W. van; Nijenhuis, K. te. Properties of Polymers: Their Correlation with Chemical Structure: Their Numerical Estimation and Prediction from Additive Group Contributions, 4th, completely rev. ed ed.; Elsevier: Amsterdam, 2009.

(23) Flores, I.; Etxeberria, A.; Irusta, L.; Calafel, I.; Vega, J. F.; Martinez-Salazar, J.; Sardón, H.; Müller, A. J. PET-Ran-PLA Partially Degradable Random Copolymers Prepared by Organocatalysis: Effect of PLA Incorporation on Crystallization and Morphology. ACS Sustain. Chem. Eng. 2019, 7 (9), 8647-8659. acssuschemeng.9b00443. https://doi.org/10.1021/acssuschemeng.9b00443.

(24) Royall, P. G.; Huang, C.; Tang, S. J.; Duncan, J.; Van-de-Velde, G.; Brown, M. B. The Development of DMA for the Detection of Amorphous Content in Pharmaceutical Powdered Materials. Int. J. Pharm. 2005, 301 (1-2), 181-191. https://doi.org/10.1016/j.ijpharm.2005.05.015.

(25) Bossion, A.; Heifferon, K. V.; Meabe, L.; Zivic, N.; Taton, D.; Hedrick, J. L.; Long, T. E.; Sardon, H. Opportunities for Organocatalysis in Polymer Synthesis via Step- 
Growth Methods. Prog. Polym. Sci. 2019, 90, 164-210. https://doi.org/10.1016/j.progpolymsci.2018.11.003.

(26) Van Krevelen, D. W.; Te Nijenhuis, K. Calorimetric Properties. In Properties of Polymers; Elsevier, 2009; pp 109-128. https://doi.org/10.1016/B978-0-08-0548197.00005-4.

(27) Physical Properties of Polymers Handbook, 2nd ed.; Mark, J. E., Ed.; Springer: New York, 2006.

(28) Matsen, M. W.; Bates, F. S. Block Copolymer Microstructures in the IntermediateSegregation Regime. J. Chem. Phys. 1997, 106 (6), 2436-2448. https://doi.org/10.1063/1.473153.

(29) Matsen, M. W.; Bates, F. S. Unifying Weak- and Strong-Segregation Block Copolymer Theories. Macromolecules 1996, 29 (4), 1091-1098. https://doi.org/10.1021/ma951138i.

(30) Hiemenz, P. C.; Lodge, T. P. Polymer Chemistry, second.; CRC press, 2007.

(31) Wang, B.; Zhang, M.; Zhang, J. M.; He, C. Q.; Dai, Y. Q.; Wang, S. J.; Ma, D. Z. Compositional and Temperature Dependence of Free Volume in Segmented Copolymer PETrPEO Studied by Positron Annihilation Lifetime Measurement. 1999, 262 (2), 195-205. 10.1016/S0375-9601(99)00559-9.

(32) Castillo, R. V.; Müller, A. J. Crystallization and Morphology of Biodegradable or Biostable Single and Double Crystalline Block Copolymers. Prog. Polym. Sci. 2009, 34 (6), 516-560. https://doi.org/10.1016/j.progpolymsci.2009.03.002.

(33) Pérez-Camargo, R. A.; Arandia, I.; Safari, M.; Cavallo, D.; Lotti, N.; Soccio, M.; Müller, A. J. Crystallization of Isodimorphic Aliphatic Random Copolyesters: 
Pseudo-Eutectic Behavior and Double-Crystalline Materials. Eur. Polym. J. 2018, 101, 233-247. https://doi.org/10.1016/j.eurpolymj.2018.02.037.

(34) Lorenzo, A. T.; Arnal, M. L.; Albuerne, J.; Müller, A. J. DSC Isothermal Polymer Crystallization Kinetics Measurements and the Use of the Avrami Equation to Fit the Data: Guidelines to Avoid Common Problems. Polym. Test. 2007, 26 (2), 222231. https://doi.org/10.1016/j.polymertesting.2006.10.005.

(35) Michell, R. M.; Lorenzo, A. T.; Müller, A. J.; Lin, M.-C.; Chen, H.-L.; Blaszczyk-Lezak, I.; Martín, J.; Mijangos, C. The Crystallization of Confined Polymers and Block Copolymers Infiltrated Within Alumina Nanotube Templates. Macromolecules 2012, 45 (3), 1517-1528. https://doi.org/10.1021/ma202327f.

(36) Michell, R. M.; Blaszczyk-Lezak, I.; Mijangos, C.; Müller, A. J. Confinement Effects on Polymer Crystallization: From Droplets to Alumina Nanopores. Polymer 2013, 54 (16), 4059-4077. https://doi.org/10.1016/j.polymer.2013.05.029.

(37) Müller, A. J.; Arnal, M. L.; Trujillo, M.; Lorenzo, A. T. Super-Nucleation in Nanocomposites and Confinement Effects on the Crystallizable Components within Block Copolymers, Miktoarm Star Copolymers and Nanocomposites. Eur. Polym. J. 2011, 47 (4), 614-629. https://doi.org/10.1016/j.eurpolymj.2010.09.027.

(38) Castillo, R. V.; Arnal, M. L.; Müller, A. J.; Hamley, I. W.; Castelletto, V.; Schmalz, H.; Abetz, V. Fractionated Crystallization and Fractionated Melting of Confined PEO Microdomains in PB- $b$-PEO and PE- $b$-PEO Diblock Copolymers. Macromolecules 2008, 41 (3), 879-889. https://doi.org/10.1021/ma0718907.

(39) Lorenzo, A. T.; Müller, A. J. Estimation of the Nucleation and Crystal Growth Contributions to the Overall Crystallization Energy Barrier. J. Polym. Sci. Part B Polym. Phys. 2008, 46 (14), 1478-1487. https://doi.org/10.1002/polb.21483. 


\section{For TOC Content Only}

Organocatalyzed polymerization of PET-mb-poly(oxyhexane) copolymers and their self-assembly into double crystalline

\section{superstructures}

Irma Flores ${ }^{1}$, Andere Basterretxea ${ }^{1}$, Agustin Etxeberria ${ }^{1}$, Alba González ${ }^{1}$, Connie Ocando $^{1}$, Juan Francisco Vega ${ }^{3}$, Javier Martínez-Salazar ${ }^{3}$, Haritz Sardon ${ }^{1 *}$, Alejandro J. Müller ${ }^{1,2^{*}}$

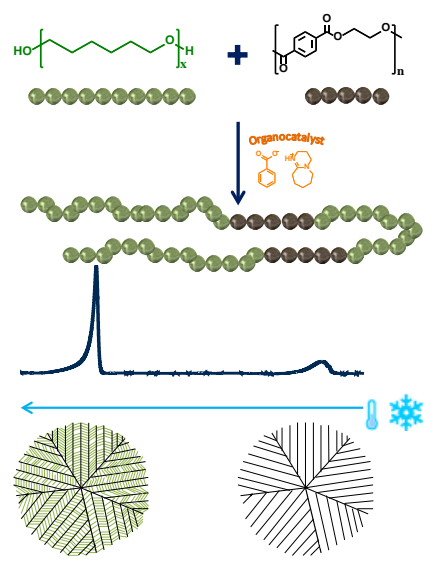

